The Cambridge Handbook of

Linguistic

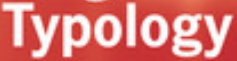

edted by Alowidra Y. Akhomidy and R. M. W, Dixon 


\section{The Cambridge Handbook of Linguistic Typology}

Linguistic typology identifies both how languages vary and what they all have in common. This handbook provides a state-of-the art survey of the aims and methods of linguistic typology, and the conclusions we can draw from them. Part I covers phonological typology, morphological typology, sociolinguistic typology and the relationships between typology, historical linguistics and grammaticalization. It also addresses typological features of mixed languages, creole languages, sign languages and secret languages. Part II features contributions on the typology of morphological processes, noun categorization devices, negation, frustrative modality, logophoricity, switch reference and motion events.

Finally, Part III focuses on typological profiles of the mainland Southeast Asia area, Australia, Quechuan and Aymaran, Eskimo-Aleut, Athabaskan (Dene), Iroquoian, the Kampa subgroup of Arawak, Omotic, Semitic, Dravidian, the Oceanic subgroup of Austronesian, and the Awuyu-Ndumut family (in West Papua). Uniting the expertise of a stellar selection of scholars, this Handbook highlights linguistic typology as a major discipline within the field of linguistics.

alexandra y. Aikhenvald is Australian Laureate Fellow, Distinguished Professor, and Director of the Language and Culture Research Centre James Cook University, Australia. She is an expert on languages and cultures of Amazonia and the Sepik region of Papua New Guinea, in addition to linguistic typology, general linguistics, language contact and several other areas.

R. M. W. DIXON is Professor and Deputy Director of the Language and Culture Research Centre at James Cook University, and a Fellow of the British Academy. He has published grammars of a number of Australian languages, a dialect of Fijian and of Jarawara, an Amazonian language. He is an expert in linguistic typology and the author of a classic three-volume work on basic linguistic theory. 
Genuinely broad in scope, each handbook in this series provides a complete state-of-the-field overview of a major sub-discipline within language study and research. Grouped into broad thematic areas, the chapters in each volume encompass the most important issues and topics within each subject, offering a coherent picture of the latest theories and findings. Together, the volumes will build into an integrated overview of the discipline in its entirety.

\section{Published titles}

The Cambridge Handbook of Phonology, edited by Paul de Lacy

The Cambridge Handbook of Linguistic Code-switching, edited by Barbara E. Bullock and Almeida Jacqueline Toribio

The Cambridge Handbook of Child Language, Second Edition, edited by Edith L. Bavin and Letitia Naigles

The Cambridge Handbook of Endangered Languages, edited by Peter K. Austin and Julia Sallabank

The Cambridge Handbook of Sociolinguistics, edited by Rajend Mesthrie

The Cambridge Handbook of Pragmatics, edited by Keith Allan and Kasia M. Jaszczolt

The Cambridge Handbook of Language Policy, edited by Bernard Spolsky

The Cambridge Handbook of Second Language Acquisition, edited by Julia Herschensohn and Martha Young-Scholten

The Cambridge Handbook of Biolinguistics, edited by Cedric Boeckx and Kleanthes K. Grohmann

The Cambridge Handbook of Generative Syntax, edited by Marcel den Dikken

The Cambridge Handbook of Communication Disorders, edited by Louise Cummings

The Cambridge Handbook of Stylistics, edited by Peter Stockwell and Sara Whiteley

The Cambridge Handbook of Linguistic Anthropology, edited by N. J. Enfield, Paul Kockelman and Jack Sidnell

The Cambridge Handbook of English Corpus Linguistics, edited by Douglas Biber and Randi Reppen

The Cambridge Handbook of Bilingual Processing, edited by John W. Schwieter

The Cambridge Handbook of Learner Corpus Research, edited by Sylviane Granger, Gaëtanelle Gilquin and Fanny Meunier

The Cambridge Handbook of Linguistic Multicompetence, edited by Li Wei and Vivian Cook

The Cambridge Handbook of English Historical Linguistics, edited by Merja Kytö and Päivi Pahta

The Cambridge Handbook of Formal Semantics, edited by Maria Aloni and Paul Dekker

The Cambridge Handbook of Morphology, edited by Andrew Hippisley and Greg Stump

The Cambridge Handbook of Historical Syntax, edited by Adam Ledgeway and Ian Roberts

The Cambridge Handbook of Linguistic Typology, edited by Alexandra Y. Aikhenvald and R. M. W. Dixon

\section{Forthcoming}

The Cambridge Handbook of Areal Linguistics, edited by Raymond Hickey The Cambridge Handbook of Cognitive Linguistics, edited by Barbara Dancygier 


\section{The Cambridge Handbook of Linguistic Typology}

Edited by

Alexandra Y. Aikhenvald and R. M. W. Dixon

Language and Culture Research Centre, James Cook University 


\section{CAMBRIDGE \\ UNIVERSITY PRESS}

University Printing House, Cambridge CB2 8BS, United Kingdom

Cambridge University Press is part of the University of Cambridge.

It furthers the University's mission by disseminating knowledge in the pursuit of education, learning and research at the highest international levels of excellence.

www.cambridge.org

Information on this title: www.cambridge.org/9781107091955

(C) Cambridge University Press 2017

This publication is in copyright. Subject to statutory exception and to the provisions of relevant collective licensing agreements, no reproduction of any part may take place without the written permission of Cambridge University Press.

First published 2017

Printed in the United Kingdom by Clays, St Ives plc

A catalogue record for this publication is available from the British Library

Library of Congress Cataloguing in Publication data

Aikhenvald, A. Y. (Aleksandra Yurievna) editor.| Dixon,

Robert M. W., editor.

The Cambridge handbook of linguistic typology / edited by Alexandra X.

Aikhenvald and R. M. W. Dixon.

Cambridge : Cambridge University Press, [2016] | Includes index.

LCCN 2016014769 | ISBN 9781107091955

LCSH: Typology (Linguistics) - Handbooks, manuals, etc.

LCC P204 .C263 2016 | DDC 410.1-dc23

LC record available at https://lccn.loc.gov/2016014769

ISBN 978-1-107-09195-5 Hardback

Cambridge University Press has no responsibility for the persistence or accuracy of URLs for external or third-party internet websites referred to in this publication, and does not guarantee that any content on such websites is, or will remain, accurate or appropriate. 


\section{Contents}

List of Figures and Diagrams

page vii

List of Tables

ix

List of Maps

xii

List of Contributors

xiii

Acknowledgements

XV

List of Abbreviations

xvi

1 Introduction: Linguistic Typology - Setting the

Scene AlexandraY. Aikhenvald and R. M. W. Dixon

Part I Domains of Linguistic Typology 37

2 Phonological Typology Harry van der Hulst 39

3 Morphological Typology Thomas E. Payne 78

4 Typology and Historical Linguistics Silvia Luraghi 95

5 Sociolinguistic Typology: Social Structure and Linguistic Complexity Peter Trudgill 124

6 Typology and Grammaticalization Heiko Narrog 151

7 Sign Language Typology Ulrike Zeshan and Nick Palfreyman 178

8 Typology of Mixed Languages Peter Bakker 217

9 Typology of Creole Languages Aymeric Daval-Markussen and Peter Bakker

10 Typology of Secret Languages and Linguistic Taboos Anne Storch

Part II Typology of Grammatical Categories

11 The Typology of Morphological Processes: Form and Function David Beck

12 A Typology of Noun Categorization Devices Alexandra Y. Aikhenvald

13 Negation Matti Miestamo 
14 Number Edith A. Moravcsik

440

15 A Typology of Frustrative Marking in Amazonian Languages Simon E. Overall

477

16 Logophoricity Felix K. Ameka

513

17 A Typology of Switch Reference John R. Roberts 538

18 Approaches to Motion Event Typology Eric Pederson

574

Part III Typological Profiles of Linguistic Areas and Language Families 599

19 Language in the Mainland Southeast Asia Area N. J. Enfield 601

20 The Australian Linguistic Area R. M. W. Dixon

624

21 A Typological Overview of Aymaran and Quechuan Language Structure Willem F. H. Adelaar

651

22 The Eskimo-Aleut Language Family Michael Fortescue

683

23 The Athabaskan (Dene) Language Family Keren Rice and Willem de Reuse

24 The Iroquoian Language Family Marianne Mithun

747

25 The Kampa Subgroup of the Arawak Language

Family Elena Mihas

782

26 The Omotic Language Family Azeb Amha

815

27 The Semitic Language Family Aaron D. Rubin

854

28 The Dravidian Language Family Sanford B. Steever

887

29 The Oceanic Subgroup of the Austronesian Language

Family Valérie Guérin

911

30 Greater Awyu Languages of West Papua in Typological

Perspective Lourens de Vries

942

Index of Authors

967

Index of Languages, Language Families and Linguistic Areas

981

Index of Subjects

992 


\section{Figures and Diagrams}

\section{Diagrams}

1.1 Nominal Hierarchy (Dixon 1994: 85)

page 9

1.2 The colour terminology hierarchy originally suggested by Berlin and Kay (1969)

\section{Figures}

2.1 Stress types in QI (top) and QS (bottom) languages (from Goedemans 2010: 654, 655)

3.1 The index of synthesis (the number of morphemes per word)

3.2 The index of fusion (the number of fusional junctures to all junctures)

3.3 The interaction between the indices of synthesis and fusion

4.1 Directionality in morphological change

6.1 Navajo verb template (according to Young and Morgan 1987: 37-8)

6.2 Paths for the development of future morphemes (Bybee 1988: 374)

6.3 Segmental effect of stress (Schiering 2007: 342; 2010: 88) 168

7.1 South Korean Sign Language sign for 'scold a female person'

7.2 'When/what day' in Turkish Sign Language

7.3 Generic interrogative of quantity and its simultaneous compounds in Japanese Sign Language

7.4 Negative movement patterns in German Sign Language (DGS)

7.5 The signs KNOW\#NEG 'not know' and TASTE^NEG 'tasteless' in Hong Kong Sign Language 
7.6 Negative affix and clitic in Ugandan Sign Language.

a. The sign LIKE and its negative counterpart with negative affix (hand moving away from the body);

b. The sign UNDERSTAND^LOW-QUALITY meaning 'not understand'

7.7 Handshapes in possessive pronouns

198

7.8 Possessive signs in South Korean Sign Language 200

7.9 Possessive sign in Turkish Sign Language 201

7.10 IPSL numerals from New Delhi 203

7.11 The numeral sign TWO\#THOUSAND in TID 204

7.12 Subtractive numeral '18' ('20 minus 2') from Mardin Sign Language (Turkey) 205

7.13 Numeral signs based on different writing systems (from Sagara 2014: 81)

7.14 Signs for '100', ‘1,000', and ‘100,000' in APSL 208

7.15 A cross-modal typological space for numerals 210

11.1 Taxonomy of morphological processes by signifier type 326

15.1 Grammaticalization path of frustrative as proposed by Dietrich (2006)

501

19.1 Phonotactic template of Kri words

19.2 The six Kri rime types, defined by intersections of terminance and register distinctions

606

22.1 Eskimo-Aleut languages and dialects

606

24.1 Genetic relationships among major Iroquoian languages 684

24.2 The six pitch patterns in Oklahoma Cherokee (Uchihara 2013: 2)

750

24.3 Iroquoian verb morphology

24.4 Iroquoian prepronominal prefixes 759

24.5 Iroquoian suffixes 760

25.1 Internal classification of Kampa (Michael 2011)

26.1 Classification of Omotic languages

784

29.1 The Austronesian language family tree 913

29.2 The Oceanic language subgroup 


\section{Tables}

3.1 Greenberg's (1954) calculations of ten typological parameters for eight languages

3.2 Fusion in Spanish verbs

3.3 Synthesis and monosyllabicity in Dinka (from Andersen 1994: 29)

6.1 The parameters of grammaticalization (Lehmann 2002: 110)

6.2 Prefixing versus suffixing in inflectional morphology (Dryer 2005: 110)

6.3 Rate of suffixation (vs. prefixation) by grammatical category (Cysouw 2006: 11)

6.4 Source schemas for predicative possessive constructions (Heine 1997: 91)

7.1 Characteristics of manual dominant and non-manual dominant systems of negation (from Zeshan 2006: 43)

7.2 Recurring formational components in negative particles

7.3 Positive and negative marking of possession in Llengua de Signes Catalana (Spain)

8.1 Lexicon of Berbice Creole (in per cent), after source languages

8.2 Etymological sources of basic vocabulary of three Surinamese creoles (from Smith 1987: 139)

9.1 Standard Arabic and Kinubi verbal paradigms (adapted from Owens 2001: 349)

10.1 Multimodal features of registers and speech styles 304

11.1 Tigrinya verb paradigms 334

11.2 Some Archi case forms for GEL 'cup' 337

11.3 Partial Kisi paradigm for cimbu 'leave' 339

$\begin{array}{ll}11.4 \text { Maasai case paradigms } & 349\end{array}$

11.5 Lealao Chinantec tonal paradigms 350

11.6 Functions of morphological processes 352

12.1 Noun classes in Bantu 365 
12.2 Mescalero Apache classificatory verb categories: 'be located'

12.3 Noun categorization devices and their scope

12.4 Preferred semantic parameters in noun categorization devices

12.5 Categorization of an inanimate noun uni 'water, waterway' in Tariana

15.1 Breakdown of frustrative markers identified

15.2 Languages showing extended functions for frustratives

15.3 Frustratives that do not fit the definition in (1)

15.4 Unrecognized frustratives

15.5 Unclear cases

15.6 Formal realization of frustrative marking

15.7 Apparent cognate sets in Tupí-Guaraní (from Jensen 1998)

15.8 'Frustrative' and related markers in Yaminahua subgroup and other Panoan languages

15.9 Frustrative suffixes in Kampa languages

15.10 Languages surveyed

17.1 Switch-reference languages

17.2 Five different types of reference-tracking systems (Comrie 1989)

17.3 Kobon switch-reference subject-agreement suffixes (Comrie 1983: 20)

17.4 Hua switch-reference subject-agreement suffixes (Haiman 1980: 65, 188)

17.5 Amele markers of switch reference (Roberts 1987)

17.6 Warlpiri switch-reference markers (Simpson and Bresnan 1983; Stirling 1993)

17.7 Person and number control over referential overlap (Roberts 1988b, 1997: 158)

19.1 A breakdown of numbers of languages in MSEA, separated into language families

19.2 Full set of phonologically distinct vowels in Kri ( $n=33$ )

19.3 Kri long vowels laid out in a standardized nine-place system, with each cell split into two registers (heavy and light)

19.4 Khmer pronouns (Huffman 1970: 356-7)

19.5 Pronouns in Kri

20.1 Canonical consonant system in Australian languages

21.1 Personal reference paradigms in La Paz Aymara (based on Yapita 1991)

21.2 Reconstructed personal reference paradigms in Quechuan

22.1 Eskimo-Aleut and its neighbours typologically compared

22.2 Nominal inflections in West Greenlandic

22.3 Verbal inflections in West Greenlandic

22.4 West Greenlandic verbal derivational affixes 
25.1 Kampa consonants $\quad 785$

25.2 Kampa vowels 786

25.3 Person and possessor marking in Nomatsiguenga (adapted from Shaver 1996: 34-35) 791

25.4 Summary of Matsigenka personal pronouns (adapted from Snell 2011: 821, 825) 794

25.5 Kampa argument index-sets $\quad 801$

25.6 Indexation patterns in ditransitive clauses 802

26.1 Consonant inventory in Omotic languages 818

26.2 First person plural inclusive and exclusive pronouns in $\begin{array}{ll}\text { four languages } & 828\end{array}$

26.3 Wolaitta basic demonstratives $\quad 829$

26.4 Nominalized demonstratives in Wolaitta 830

27.1 Proto-Semitic consonant phonemes 860

27.2 Classical Arabic independent pronouns 865

27.3 Jewish Algerian Arabic 865

27.4 Northeastern Neo-Aramaic Jewish dialect of Challa 865

27.5 Proto-Semitic case endings 869

27.6 Old Babylonian Akkadian numerals 872

29.1 Consonant phonemes in Tinrin (Osumi 1995: 16) 916

29.2 Decrease in consonantal phonemes in the Pacific (from Trudgill 2004: 310) 916

29.3 Independent personal pronouns as subject in Boumaa Fijian (Dixon 1988: 54)

29.4 Third person independent subject pronouns in Cheke Holo (White 1988: xvii)

29.5 Realis and irrealis subject markers in Kokota (Palmer 2009: 241) 


\section{Maps}

19.1 Mainland Southeast Asia: present-day Cambodia, Laos, Vietnam, Thailand and neighbouring parts of China, Malaysia and Myanmar. (C) N. J. Enfield

20.1 The languages of Australia referred to. (C) R. M. W. Dixon 625

21.1 Aymaran and Quechuan languages. (C) W. F. H. Adelaar, previously published in The Languages of the Andes: $169 \mathrm{ed}$. Willem Adelaar and Pieter C. Muysken

23.1 Athabaskan languages. (C) Keren Rice (reproduced by David Cox for Cambridge University Press)

24.1 Iroquoian languages in North America. Licensed under Wikipedia Commons (reproduced by David Cox for Cambridge University Press)

24.2 Iroquoians at first contact. (C) Geological Survey (reproduced by David Cox for Cambridge University Press)

24.3 Iroquois five nations. (C) Canadian Encyclopedia (reproduced by David Cox for Cambridge University Press)

25.1 Kampa languages of Peru. (C) Elena Mihas (this version redrawn by David Cox)

26.1 Omotic languages. Reproduced with kind permission of Professor Dr Zygmunt Frajzyngier

27.1 Classical Semitic languages. (C) Aaron Rubin 858

27.2 Modern Semitic languages. (C) Aaron Rubin

28.1 The Dravidian languages. (C) Sanford Steever

29.1 Geographical coverage of the Austronesian language family. (C) Valérie Guérin (reproduced by David Cox for Cambridge University Press)

30.1 Greater Awyu-Ndumut languages. (C) Lourens de Vries (reproduced by David Cox for Cambridge University Press) 


\section{Contributors}

Willem F. H. Adelaar, Professor, Leiden University Centre for Linguistics, Leiden University, W.F.H.Adelaar@hum.leidenuniv.nl

Alexandra Y. Aikhenvald, Distinguished Professor and Director, Language and Culture Research Centre, James Cook University, alexandra.aikhenvald@jcu.edu.au

Felix K. Ameka, Professor, Leiden University Centre for Linguistics, F.K.Ameka@hum.leidenuniv.nl

Azeb Amha, Researcher, Africa Studies Centre, Leiden University, A.Amha@asc.leidenuniv.nl

Peter Bakker, Professor, University of Aarhus, linpb@cc.au.dk

David Beck, Professor, University of Alberta, dbeck@ualberta.ca

Aymeric Daval-Markussen, PhD scholar, University of Aarhus, linadm@cc.au.dk

R. M. W. Dixon, Professor and Deputy Director, Language and Culture Research Centre, James Cook University, Robert.Dixon@jcu.edu.au

N. J. Enfield, Professor, The University of Sydney, nick.enfield@sydney. edu.au

Michael Fortescue, Emeritus Professor, University of Copenhagen, fortesq@hum.ku.dk

Valérie Guérin, Adjunct Research Fellow, Language and Culture Research Centre, James Cook University, Valerie.Guerin@jcu.edu.au

Harry van der Hulst, Professor, University of Connecticut, harry.van.der. hulst@uconn.edu

Silvia Luraghi, Professor, Università degli Studi di Pavia, luraghi@unipv.it

Matti Miestamo, Professor, General Linguistics, University of Helsinki, matti.miestamo@helsinki.fi

Elena Mihas, PostDoctoral Research Associate, Language and Culture Research Centre, James Cook University, Elena.Mihas@jcu.edu.au 
Marianne Mithun, Professor, University of California at Santa Barbara, mithun@linguistics.ucsb.edu

Edith Moravcsik, Professor Emerita, University of Wisconsin-Milwaukee, edith@uwm.edu

Heiko Narrog, Professor, Tohoku University, narrog@gmail.com

Simon E. Overall, PostDoctoral Research Fellow, Language and Culture Research Centre, James Cook University, Simon.Overall@jcu.edu.au

Nick Palfreyman, Research Fellow, International Institute for Sign Languages and Deaf Studies (iSLanDS), University of Central Lancashire, nickpalfreyman@cantab.net

Thomas E. Payne, Research Associate, University of Oregon and Senior Linguistics Consultant, SIL International, tpayne@uoregon.edu

Eric Pederson, Professor, University of Oregon, epederso@uoregon.edu Willem de Reuse, Research Professor, University of North Texas, WillemDeReuse@my.unt.edu

Keren Rice, Professor, University of Toronto, rice@chass.utoronto.ca

John R. Roberts, Senior Linguistics Consultant, SIL International, dr_john_roberts@sil.org

Aaron D. Rubin, Professor, Penn State University, arubin@psu.edu

Sanford Steever, Independent scholar, New Canaan, Connecticut, sbsteever@yahoo.com

Anne Storch, Professor, Institut für Afrikanistik, University of Cologne, astorch@uni-koeln.de

Peter Trudgill, Professor, University of Agder, peter.trudgill@unifr.ch

Lourens de Vries, Professor, Free University of Amsterdam, 1.j.de. vries@vu.nl

Ulrike Zeshan, Professor and Director of the International Institute for Sign Languages and Deaf Studies (iSLanDS), University of Central Lancashire, uzeshan@uclan.ac.uk 


\section{Acknowledgements}

We owe the idea of putting this book together to Helen Barton, at Cambridge University Press. Without her unfailing support and assistance at every stage, this project would not have been possible. We are grateful to all the contributors to this volume, for their chapters and for the comments we received. Many thanks go to Professor Nola Alloway, Dean of the College of Arts, Society and Education at James Cook University for her moral and financial support. We owe a special debt of gratitude to Brigitta Flick and Jolene Overall, for meticulous editorial assistance, checking the manuscripts and formatting them. A very big thank you goes to Amanda Parsonage for her assistance and support at the Language and Culture Research Centre. 


\section{Abbreviations}

1

$1>2,2>3$, etc.

2

3

3.3.CJ

4

A

$\mathrm{ABE}$

$A B L$

$\mathrm{ABS}$

ACC

ACT

$\mathrm{AD}$

$A D D$

ADEL

ADJ

ADJZ

$A D V$

ADVST

AFF

aFOC

A G

AGAIN

AGR

AGT

AL first person

first person acts on second person, second person acts on third person, etc.

second person

third person

third person subject with third person object conjunct order verb

first person inclusive or fourth person, impersonal pronoun

transitive subject function; Actor macrorole; Actor abessive

ablative

absolutive

accusative

active

addressee deictic

additive

adelative

adjective

adjectivizer

adverb

adversative

affirmative

argument focus marker

agentive

repetitive aspect, topic shift

agreement

agent

alienable 


\begin{tabular}{|c|c|}
\hline ALL & allative \\
\hline $\mathrm{AN}$ & Austronesian \\
\hline AN & animate \\
\hline ANA & action narrowly averted \\
\hline ANAPH & anaphoric \\
\hline AND & andative non-singular, singular transitive \\
\hline ANIM.INTR & animate intransitive \\
\hline ANP & adnominal verb \\
\hline ANT & anterior \\
\hline ANTIC & anticipatory \\
\hline ANTICAUS & anticausative \\
\hline ANTIP & antipassive \\
\hline AntSu & anticipatory subject \\
\hline AOR & aorist \\
\hline APPL.APPLIC & applicative \\
\hline APPL.GEN & general applicative \\
\hline APPL.PRES & presential applicative \\
\hline AREA & areal \\
\hline APR & apprehensive \\
\hline ARG & argument \\
\hline ART & article \\
\hline ASS.P & associative plural \\
\hline ASP & aspect \\
\hline Ass & assertive \\
\hline ASSOC & associative \\
\hline ATR & Advanced Tongue Root \\
\hline ATTN & attenuative \\
\hline aug & augmented \\
\hline AUX & auxiliary \\
\hline Aym & Aymaran \\
\hline BEN & benefactive \\
\hline$c$ & common gender; consonant; controlling clause \\
\hline C.EXIST & ceased existence \\
\hline CAUS & causative \\
\hline CIRC & circumstantial \\
\hline CIS & cislocative \\
\hline $\mathrm{CJ}$ & conjugation \\
\hline $\mathrm{CL}$ & class \\
\hline CLF & classifier \\
\hline CLT & clitic \\
\hline CMPL & completive \\
\hline CND & conditional \\
\hline CNG & connegative \\
\hline $\mathrm{CNJ}$ & conjunctive verb \\
\hline CNSTR & construct \\
\hline
\end{tabular}




\begin{tabular}{|c|c|}
\hline CNTREXP & counterexpectation \\
\hline CNTR.FACT & counterfactual condition \\
\hline CNV & converb \\
\hline COMIT & comitative affix \\
\hline COMP & complementiser \\
\hline COMPL & completive \\
\hline COND & conditional \\
\hline CONJ & conjectural (evidential)/conjunction \\
\hline CONN & connective \\
\hline CONSTR & construct \\
\hline CONT & contemporative \\
\hline CONTIN & continuative \\
\hline CONTR & contrast \\
\hline CONV & converb \\
\hline COORD & coordination \\
\hline COP & copula \\
\hline $\mathrm{CT}$ & circumstantial topic; class term \\
\hline CUST & customary \\
\hline CVB & converb \\
\hline $\mathrm{D}$ & dependent \\
\hline D.CLF & d-classifier \\
\hline DAT & dative \\
\hline $\mathrm{DEC}, \mathrm{DECL}$ & declarative \\
\hline DEF & definitive; definite \\
\hline DEIC & deictic particle \\
\hline DEM & demonstrative \\
\hline DepSu & dependent clause subject \\
\hline DESID & desiderative \\
\hline DET & determiner \\
\hline DIM & diminutive \\
\hline DIR & directive; directional \\
\hline DIST & distal \\
\hline DISTR & distributive \\
\hline DL & dual \\
\hline DNA & Direct Negation Avoidance \\
\hline DO & direct object \\
\hline DOM & differential object marking \\
\hline DR & different reference \\
\hline DS & different subject \\
\hline DSTL & distal demonstrative \\
\hline DU & dual \\
\hline DUR & durative aspect \\
\hline DV & duplicative \\
\hline E & epenthetic element \\
\hline EMP, EMPH & emphatic \\
\hline
\end{tabular}




\begin{tabular}{|c|c|}
\hline EP & epenthetic \\
\hline ERG & ergative \\
\hline ES & echo subject \\
\hline EV & direct evidential \\
\hline EVI & evidential \\
\hline EX & existential \\
\hline EXC, eXC, EXCL & exclusive \\
\hline EXH.FOC & exhaustive focus \\
\hline EXIST & existential \\
\hline EXP & experienced \\
\hline$F, f$ & feminine \\
\hline FACT & factitive \\
\hline FAR.PST & far past \\
\hline FEM & feminine \\
\hline $\mathrm{FI}$ & feminine/indefinite \\
\hline $\mathrm{Fj} / \mathrm{J}$ & $\begin{array}{l}\text { the ratio of fusional morpheme junctures to all mor- } \\
\text { pheme junctures }\end{array}$ \\
\hline $\mathrm{FOC}$ & focus \\
\hline FoOT & 'foot' as body part prefix \\
\hline FP & free pronoun \\
\hline FREQ & frequentative \\
\hline fric & fricative \\
\hline FRUST & frustrative \\
\hline FS & factual stem \\
\hline FUT & future \\
\hline GEN & genitive \\
\hline GENZ & generalized \\
\hline GER & gerund \\
\hline $\mathrm{H}$ & high tone or pitch \\
\hline HAB & habitual \\
\hline HEDGE & hedging device \\
\hline $\mathrm{HL}$ & Highlighter \\
\hline $\mathrm{HN}$ & head noun \\
\hline HON & honorific \\
\hline HRSY & hearsay \\
\hline HUM & human \\
\hline IDPH & ideophone \\
\hline $\mathrm{IE}$ & Indo-European \\
\hline IMMED & immediate \\
\hline IMP & imperative \\
\hline IMPERS & impersonal \\
\hline IMPF & imperfective \\
\hline IMPL & implicated \\
\hline IMPST & immediate past \\
\hline INAL & inalienable \\
\hline
\end{tabular}




\begin{tabular}{|c|c|}
\hline INAN & inanimate \\
\hline INC, inc & inclusive \\
\hline INCEP & inceptive \\
\hline INCL & inclusive \\
\hline INCOMPL & incompletive \\
\hline IND & indicative \\
\hline INDEF & indefinite \\
\hline INDEP & independent \\
\hline INESS & inessive \\
\hline INF & infinitive \\
\hline INFL & inflection \\
\hline INFR & inferred evidential \\
\hline INFRN & inferential \\
\hline INGR & ingressive \\
\hline INST & instrumental \\
\hline INSV & inessive \\
\hline INT & intensifier \\
\hline INTENT & intentional \\
\hline INTER & interrogative \\
\hline INTERJ & interjection \\
\hline INTR & intransitive \\
\hline INTS & intensive \\
\hline INTSINT & International Transciption System for Intonation \\
\hline INV & inverse \\
\hline IPFV & imperfective \\
\hline IRR & irrealis \\
\hline ITER & iterative \\
\hline IT G & intangible \\
\hline IVC & impersonal verb construction \\
\hline KBo & Keilschrifttexte aus Boghazköi \\
\hline L & low tone or pitch \\
\hline LF & low fall \\
\hline LIG & ligature \\
\hline LIM & limitative case \\
\hline LK & linker \\
\hline LOC & locative \\
\hline LOC.CL & locative classifier \\
\hline LOG & logophoric pronoun \\
\hline $\log A$ & speaker logophoric pronoun \\
\hline $\log B$ & addressee logophoric pronoun \\
\hline LP & linking particle \\
\hline $\mathrm{M}, \mathrm{m}$ & masculine \\
\hline M & mid tone \\
\hline
\end{tabular}




\begin{tabular}{|c|c|}
\hline MAL & malefactive \\
\hline MASC & masculine \\
\hline MED & medial (function similar to that of 'converb') \\
\hline MID & middle \\
\hline $\min$ & minimal \\
\hline MIR & mirative \\
\hline MOD & modifier \\
\hline M.PL.AGT & masculine plural agent \\
\hline $\mathrm{M} / \mathrm{W}$ & the number of morphemes per grammatical word \\
\hline $\mathrm{N}$ & neuter gender; noun \\
\hline N.AGT & non-agentive \\
\hline NARR & narrative marker \\
\hline $\mathrm{NCL}$ & noun class \\
\hline NEG & negative \\
\hline NENA & Northeastern Neo-Aramaic \\
\hline NEWSIT & new situation \\
\hline $\mathrm{NF}$ & non-finite; non-feminine \\
\hline NFUT & non-future \\
\hline NFS & non-factual stem \\
\hline $\mathrm{NH}$ & non-human \\
\hline NHYP & non-hypothetical \\
\hline $\mathrm{NM}$, nmasc & non-masculine \\
\hline $\mathrm{n}-\mathrm{min}$ & non-minimal \\
\hline NMLZ & nominalizer \\
\hline NMR & non-macrorole argument \\
\hline $\mathrm{NMZ}$ & nominalizer \\
\hline NOM & nominative \\
\hline NOML & nominal \\
\hline NON-EXP & non-experienced \\
\hline NONFUT & non-future \\
\hline NONPUNCT & nonpunctual \\
\hline NON3 & non-third person \\
\hline NON_SBJ & non-subject \\
\hline NOUN.CL & noun classifier \\
\hline NP & noun phrase \\
\hline NPST & nonpast \\
\hline NREF & non-referential \\
\hline NS & non-singular \\
\hline NSG, nsg, n-sg & non-singular \\
\hline NTS & non-topic subject \\
\hline NUM.CL & numeral classifier \\
\hline 0 & object \\
\hline OBJ & object \\
\hline OBL & oblique \\
\hline OBV & obviative \\
\hline
\end{tabular}




\begin{tabular}{|c|c|}
\hline OPT & optative \\
\hline ov & object-verb order \\
\hline $\mathrm{P}$ & patient-like \\
\hline $\mathrm{p} 2$ & second position \\
\hline PAA & Proto-Afroasiatic \\
\hline PAR & partitive \\
\hline PART & participle \\
\hline PART.SG & partitive singular \\
\hline PASS & passive \\
\hline PAT & patient \\
\hline $\mathrm{PD}$ & Proto-Dravidian \\
\hline PERF & perfective aspect \\
\hline PERS & person \\
\hline PERT & pertensive \\
\hline $\mathrm{pF}$ & perfect \\
\hline PFV & perfective \\
\hline PI & polar interrogative \\
\hline PIE & Proto-Indo-European \\
\hline PK & personal knowledge \\
\hline PL, pl, plur, PLUR & plural \\
\hline PNG & person/number/gender \\
\hline POC & Proto-Oceanic \\
\hline POL & polite \\
\hline Pos & positive \\
\hline Poss & possessive; possession \\
\hline POSS.CL & possessive classifier \\
\hline POSTP & postpositional \\
\hline POSTP:PURP & purposive postpositional \\
\hline POT & potential \\
\hline PP & past perfect \\
\hline $\mathrm{pP}, \mathrm{Pp}$ & postposition; positive polarity \\
\hline $\mathrm{PR}$ & present \\
\hline PR.PART & pragmatic particle \\
\hline $\operatorname{Pr}$ & preposition \\
\hline PRED & predicate \\
\hline PREP & preposition \\
\hline PRES & present \\
\hline PRF & prefix \\
\hline PRO & pronoun \\
\hline PROG & progressive \\
\hline PROX & proximal \\
\hline PRS.PRF & present perfect tense \\
\hline PRT & preterit \\
\hline PS & past \\
\hline PSA & privileged syntactic argument \\
\hline
\end{tabular}




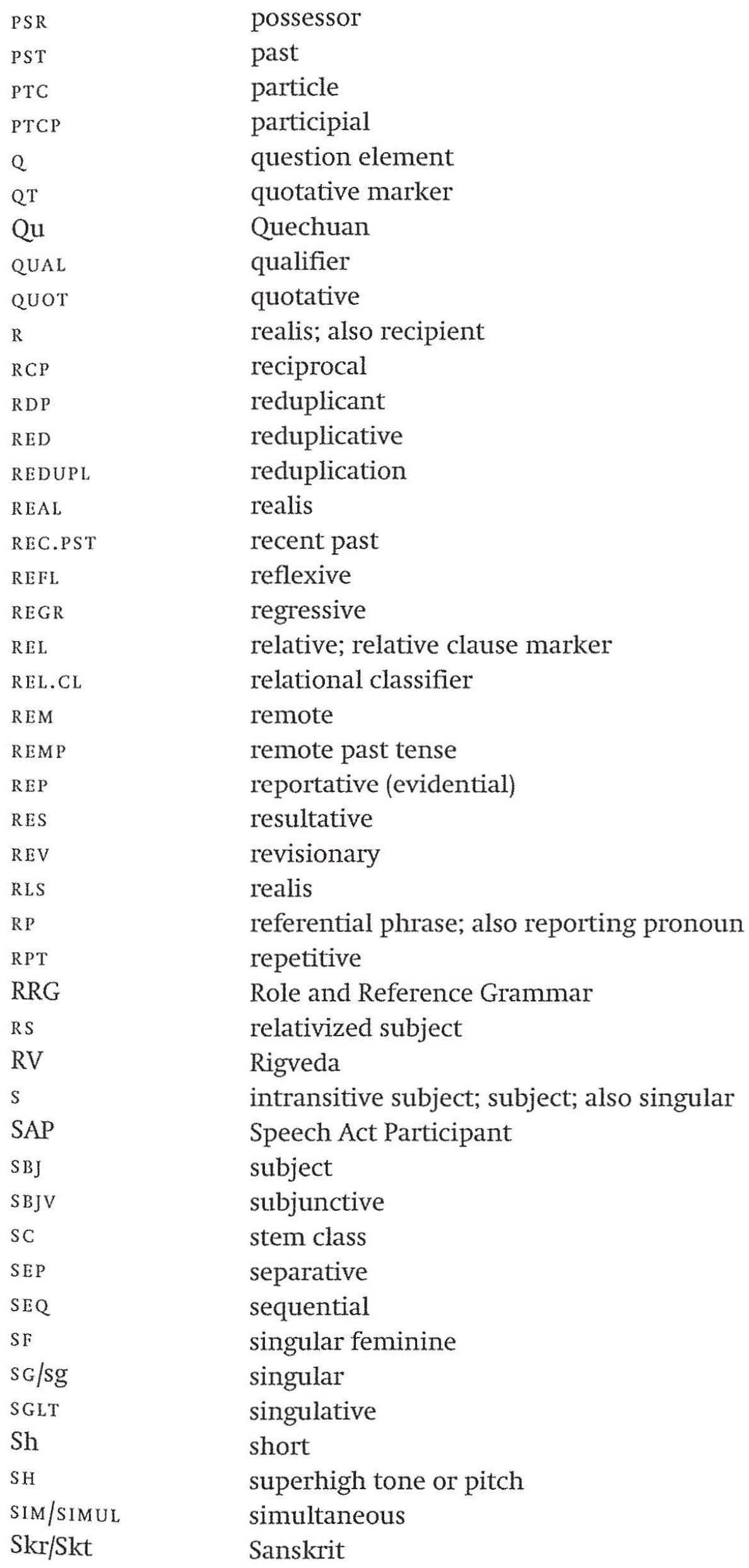




\begin{tabular}{|c|c|}
\hline$S M$ & singular masculine \\
\hline SMI & semeliterative \\
\hline SMR & same reference \\
\hline SN & singular neuter \\
\hline so & same object \\
\hline SOC & sociative \\
\hline sov & subject-object-verb order \\
\hline SP & specifier \\
\hline SQ & sequential \\
\hline$S R$ & switch reference \\
\hline sS & same subject \\
\hline StBoT & Studien zu den Bogazköy-Texten \\
\hline ST.PL & stative plural \\
\hline STAT & stative \\
\hline STR & strong \\
\hline StressTyp & stress typology database \\
\hline SU, SUB, SUBJ & subject \\
\hline SUBJV & subjunctive \\
\hline SUBORD & subordinate \\
\hline SUFF & suffix \\
\hline svo & subject verb order \\
\hline SylTyp & syllable typology database \\
\hline $\mathrm{T}$ & theme \\
\hline TI2 & transitive inanimate verb type 2 \\
\hline TA & transitive animate verb \\
\hline TAM & tense and/or aspect and/or modality and/or mood \\
\hline TEL. & telic, contrastive emphasis \\
\hline TEMP & temporal \\
\hline TERM & terminative \\
\hline THM & thematic \\
\hline ToBI & tone and break indices \\
\hline TODP & today's past tense \\
\hline TOP & topic \\
\hline Tot & totalitative \\
\hline TR, TRANS & transitive \\
\hline TRC & transitive controlling clause \\
\hline TRM & terminative derivational suffix \\
\hline TR.2 & type 2 transitive verb \\
\hline TV & terminal vowel \\
\hline $\mathrm{U}$ & undergoer macrorole \\
\hline ua & unit augmented \\
\hline UNSP & unspecified \\
\hline UPSID & Universal Phonological Segment Inventory Database \\
\hline $\mathrm{V}, \mathrm{VB}$ & verb \\
\hline VD & voiced \\
\hline
\end{tabular}




\begin{tabular}{|c|c|}
\hline VBZ & verbalizer \\
\hline $\mathrm{vcl}$ & voiceless \\
\hline VCL & verbal classifier; also verb closing element \\
\hline VIS & visual evidential \\
\hline VL & voiceless \\
\hline $\mathrm{VN}$ & verbal noun \\
\hline vo & verb-object order \\
\hline VOC & vocative \\
\hline VOT & voice onset time \\
\hline vow & vowel \\
\hline $\mathrm{VP}$ & verb phrase \\
\hline vso & verb-subject order \\
\hline vv & voice/valence \\
\hline Xtone & cross-linguistic tonal database \\
\hline \multicolumn{2}{|c|}{ Glosses for Sign Languages } \\
\hline SIGN & gloss for a manual sign \\
\hline SIGN-SIGN & $\begin{array}{l}\text { hyphenated gloss for a single sign that needs more } \\
\text { than one word to express its meaning }\end{array}$ \\
\hline SIGN- & sign held in its final position for a length of time \\
\hline IX or INDEX & $\begin{array}{l}\text { pointing signs, followed by further information about } \\
\text { the reference of the point }\end{array}$ \\
\hline 1,2 & $\begin{array}{l}\text { subscripts indicating first and second person } \\
\text { reference }\end{array}$ \\
\hline SIGN\#SIGN & simultaneous morphology \\
\hline $\mathrm{SIGN}^{\wedge} \mathrm{SIGN}$ & host-clitic combination \\
\hline t & non-manual marking for topicalisation \\
\hline $\mathrm{y} / \mathrm{n}$ & non-manual marking for polar question \\
\hline low-br & lowered eyebrows \\
\hline brow-raise & raised eyebrows \\
\hline _neg-tilt & $\begin{array}{l}\text { backward head tilt for negation } \\
\text { clause boundary }\end{array}$ \\
\hline
\end{tabular}

\section{Further Conventions}
$=\quad$ clitic break
- affix boundary
$\approx$ varies with





\section{1 \\ Introduction: Linguistic Typology - Setting the Scene}

Alexandra Y. Aikhenvald and R. M. W. Dixon

Linguistic typology as a discipline is all-embracing. Its subject matter is rigorous scientific investigation of cross-linguistic variation in every domain of language, and thus of the limits and of the possibilities of human language. Typology investigates kinds of linguistic phenomena within a language, and across languages. It may also delineate types of languages and classify them.

Typologists work out constraints on language structures and formulate predictions as to what one could expect in a language. Typology is central for inductively based cross-linguistic generalizations. And it is a testing ground for any theoretical statement about what a language, or a language feature, may be like. Typological generalizations - based on good-quality reliable sources - help predict what is more likely, and what is less likely, to occur in a language. Ideally, typology goes hand in hand with explanation - why the language is the way it is. In this introductory chapter, we address linguistic typology in its various guises, offering a brief glimpse into typological parameters, the scope of linguistic typology and its relationship with linguistic analysis, historical linguistics and language contact. The last section presents an overview of this volume.

\subsection{Linguistic Typology in lts Various Guises}

Linguistic typology involves a number of interrelated areas of intellectual pursuit.

FirstLy, typology is a comprehensive investigation of cross-linguistic variation. A major premise of linguistic typology is, in Comrie's (1990: 139) words, 'that different languages vary in a number of different respects', and, 'more importantly, that this cross-linguistic variation is amenable to 
systematic study'. ${ }^{1}$ It aims at uncovering, and understanding, the range of structures and parameters available in human languages for expressing a wide variety of core concepts.

SECONDLY, typology involves establishing cross-linguistic generalizations that hold for all, or most, human languages, and correlations between linguistic phenomena. These generalizations are often called 'language universals'.

Language universals can be absolute. A statement that every spoken language has vowels and consonants holds everywhere and is an 'absolute' universal. So does a statement that every language has a way of asking a question, forming a command, or articulating negation.

Universals also reflect tendencies which are well attested crosslinguistically. A statement that languages tend to have more oral than nasal vowels reflects such an overall tendency. A universal tendency can be phrased as an implicature. An example of an 'implicational universal' is a statement that if a language has a high front nasal vowel, it will also have a low front nasal vowel. ${ }^{2}$ Implicational universals may allow us to understand the reason 'why' language is the way it is, and even predict the ways in which it might develop. Absolute universals - which have no exceptions whatsoever - are few. Most statements of general value are cast in the form of universal tendencies which allow some exceptions, but hold overall. For instance, Greenberg's (1963: 95) Universal 45 states 'If there are gender distinctions in the plural of the pronoun, there are some gender distinctions in the singular also.' There are just a few exceptions to this statement - for instance, independent personal pronouns in Tamachek, a Tuareg Berber language, distinguish masculine and feminine genders in all three persons in the plural, but only in the second person in the singular. ${ }^{3}$

Linguistic typology helps establish correlations between subparts of languages. A choice made in one part of a linguistic system may limit a set of options in some other area. For example, if a language has multiword discontinuous serial verb constructions, it is likely to be analytic (rather than synthetic) in its morphological structure. If a language has an overt marker for plural number on nouns with inanimate reference (such as 'tree' or 'house'), it is pretty much bound to also mark number on nouns with animate and human reference (such as 'dog' or 'man'). ${ }^{4}$

Finally, linguistic typology aims at offering explanations - why there are certain linguistic universals and universal tendencies, and what their limits may be. ${ }^{5}$ There is here a direct link to how humans communicate and perceive the world around them, and how languages may reflect physical, social and cultural environment.

Linguistic typology is often viewed - in a somewhat restrictive way - as a classification of languages by their synchronic grammatical features, 'according to their general structure rather than according to their historical or geographical relationship' (Bazell 1958: 3). This is congruent with 
a general non-specifically linguistic understanding of the term 'typology', as 'the study of classes with common characteristics; classification' (as given in The Oxford English dictionary online). Typological classifications have indeed gained some currency, and features and parameters employed in such procedures have been helpful in understanding how human languages work. This is what we turn to now.

\subsection{Typological Parameters and the Scope of Typology}

A typology of languages can aim at encompassing the totality of linguistic structure under one parameter. Or it can deal with one domain of language structure. We now turn to the scope of linguistic typology, and typological parameters.

\subsubsection{Typological Classification and Typological Parameters}

A typological parameter may aim at classifying a language as belonging to a general type. ${ }^{6}$ Earlier typological endeavours aimed at a classification of languages into morphological types based on the number of morphemes per word and on the techniques of combining morphemes into words.

In the first instance, languages were classified depending on whether words neatly divide into meaningful parts (morphemes) with one meaning each (further discussion is in Payne, Chapter 3 of this volume). This involves three ideal types:

i. ISolating languages, like Vietnamese and Mandarin Chinese, where every form has one meaning.

ii. AGGLUTINATING languages, like Turkish, where a form may consist of several morphemes but the boundaries between them are clear-cut.

iii. FUSIONAL languages, like Latin, where one form combines many meanings and is not easily segmentable.

An agglutinating language typically has a one-to-one correspondence between a morpheme and its meaning. A morpheme tends to have an invariant shape which makes it easy to identify. For instance, in Turkish ev-ler-im-de (house-plural-1sg-locative) 'in my houses' every morpheme corresponds to a string of one or several phonemes. In a Fusional language, like Latin, morphemes which have to be distinguished grammatically combine into one hard-to-parse form. For instance, $i$, the shortest form in Latin, has a complex meaning of 'you singular go! (imperative)'.

This erstwhile tripartite typological classification assumed that affixation is the only morphological process. To amend this, Sapir (1921: 126) posited a fourth type of language, where morpheme junctures are characterized by 'internal changes (reduplication, vocalic and consonantal 
change, changes in quantity, stress and pitch)'. He called this language type 'symbolic' (the term, and the concept, are rarely used today; see Beck, Chapter 11 of this volume, for a detailed typological analysis of morphological processes across the world's languages). However, hardly any language fits one type exactly. There tends to be a mixture of techniques. Quite a few languages are best referred to as 'basically agglutinating with some fusion'. For instance, Tariana, an Arawak language from Brazil, allows for some change of form on prefixal boundaries, but not on suffixal ones. The classificatory parameters are still in use, but they are hardly exclusive. ${ }^{7}$

Alternatively, languages can also be classified depending on a number of meaningful parts - that is, morphemes - within a word.

i. ANALYTIC languages tend to have a one-to-one correspondence between word and morpheme; they have few if any bound morphemes. Vietnamese and Mandarin Chinese are good examples of analytic languages.

ii. In synthetic languages, a word consists of several morphemes, and there are numerous bound morphemes. Hungarian and Latin are synthetic languages. Some languages are only mildly synthetic. In English, and in many languages of the Jê family from South America, the number of morphemes per word is often not more than two. Languages of the Eskimo-Aleut family such as Yupik and Greenlandic, and many languages of Amazonia, North America and northern Australia are at the opposite extreme: a word often contains a long string of morphemes (see Chapters 22-25).

In highly synthetic languages, bound morphemes express notions that would be expressed with lexical items in languages which are less synthetic. An example from Mohawk, a Northern Iroquoian language (Mithun, Chapter 24 of this volume, example 29), shows just how much information can be packed into one verb.
Ahsani'tskwahra'tsherakarhátho'
aa-hs-[an-i'tskw-a-hr-a'tsher]-a-karhat-ho-'
IRR-2 SG.AGT-[MID-rump-LINKER-Set.on-NMLZ]-LINKER-turn-
REVERSIVE-PFV
'You might [thing you set your rump on] tip over' = 'You might tip over a chair'

The term 'polysynthetic' describes such highly synthetic 'mega-rich' structures. $^{8}$

The degree of synthesis and the treatment of morphological boundaries are relatively independent typological parameters. However, they do intersect. A highly analytic language will tend to be isolating, as is the case in Mandarin Chinese and Vietnamese. For instance, Turkish is synthetic and agglutinating, and Latin is synthetic and fusional. English has strong 
analytic tendencies and is fusional. The two sets of parameters differ in yet another way. Each of 'isolating', 'agglutinating' and 'fusional' may be used to characterize the treatment of morphological boundaries in a language. 'Synthetic' and 'analytic', on the other hand, refer to a continuum. A language can be more, or less, synthetic or analytic.

Morphological typology based on these two sets of properties dominated linguistic typology as a major parameter for classifying a language as a whole, throughout the nineteenth and early twentieth century. Thomas Payne, in Chapter 3, offers a detailed analysis of history and approaches to morphological typology. ${ }^{9}$

A further parameter for classification of languages, originally put forward by Greenberg (1966), concerns the order of the meaningful elements. This originally included position of bound morphemes within a word (prefixes and suffixes), order of words within noun phrases and order of constituents within a clause or a sentence. The order of syntactic constituents within a clause varies across languages. In English, the verb has to follow the subject, as in I saw a dog. But in Fijian, the verb generally comes first. So, English is verbmedial, and Fijian is verb-initial, while Manambu, from New Guinea, is verb-final. Order of individual words within a constituent - especially a noun phrase - is another parameter. For instance, English and Latin have prepositions which come before the noun (as in post hominem and its English translation 'after (a) man'), Hungarian has postpositions which come after the noun, as in ember után (man after) 'after a man', and Estonian has both, as in sõja pärast (war:genitive.singular after/because) 'because of the war' and pärast sõda (after war:partitive. singular) 'after the war'.

A typology of languages based on the order of elements involves some correlations between orders within different kinds of constituents. For instance, languages with verb-initial constituent order tend to have prepositions (as does, for instance, Modern Welsh). Languages with a subject-object-verb order are likely to have postpositions; within a noun phrase, with possessor and adjective modifiers preceding the head noun.

Both morphological typology and the typology based on the order of meaningful elements attempt at classifying languages as systems in their totality. The typology of order of meaningful elements was perhaps the first attempt, in linguistic typology, to establish implicational relations between different features within a language. It demonstrated that typological generalizations may have a predictive power. ${ }^{10}$

A further typological parameter for an overall classification of languages was suggested by Nichols (1986). Languages are divided into head-marking and dependent-marking (verb is seen as 'head' of a clause). In a dependent-marking language, the morphological information 
concerning the relationship between the head and its dependents will attach to the dependent. For example, in Japanese, a dependent-marking language, the verb is unmarked for the relations with its dependents. The dependents (e.g. nouns or pronouns expressing arguments or obliques) are marked with post-nominal 'particles' for a particular relation they have with the verb as head. This is illustrated in (2):

(2) Taroo ga Ziroo ni hon o yatta

Taro Nom Jiro DAT book ACC gave

'Taro gave a book to Jiro'

A typical head-marking language is Abkhaz, from the north-west Caucasian family. Here only the verb, as head of the clause, is marked for the person, number and noun class of its arguments. The arguments themselves are not marked:

$$
\begin{aligned}
& \text { a-xàc'a } \quad a-p \hbar^{\circ} \text { ว̀s } \quad a-\check{s}^{\circ} q^{\circ} \text { ’̀̀ } \quad(\emptyset-) \text { lò-y-teyt' } \\
& \text { the-man the-woman the-book it-to:her-he-gave } \\
& \text { 'The man gave the book to the woman' }
\end{aligned}
$$

Many languages (including Indo-European) display features of both head- and dependent-marking. The applicability of this binary division depends on the theoretical orientation of the scholars. Many have argued against extending the notion of head from a noun phrase to a clause. $^{11}$

A typological parameter can focus on a subpart of a language. One such parameter involves the expression of prototypical grammatical relations in a clause. The universal grammatical relations within a clause are A (transitive subject), S (intransitive subject) and $O$ (object) (see Dixon 1994, 2010a: 98-9). Some languages mark $S$ and $O$ in the same way (absolutive case) and A differently (ergative case). Others mark S and $\mathrm{A}$ in the same way (nominative case) and $O$ differently (accusative case). Languages can thus be classified as absolutive-ergative or as nominative-accusative. And there may be other localized parameters, each of which helps investigate the limits and the possibilities of typological variation in one particular domain.

We now turn to the modes of typological investigation of linguistic phenomena.

\subsubsection{What to Compare: Two Modes of Linguistic Typology}

Two basic modes of linguistic typology are intra-language typology and extra-language typology. The two are intertwined.

Intra-language typology involves comparing a feature in one language with similar features in other languages, in terms of a defined set of theoretical parameters. A typological study can investigate the following, across languages: 
- Structures - for instance, the make-up of a syllable, a word or other unit in phonology, or of a complex predicate, or a noun phrase, or a clause in grammar;

- Systems - for instance, system of tense-aspect choices, or number systems, in grammar, or consonant systems in phonology;

- Construction types in grammar - for instance, relative clause constructions, speech report constructions or complement clause constructions;

- Mechanisms of marking particular categories - for instance, marking of possession within a noun phrase or a clause, or syntactic relations within a clause.

Any phenomenon in language can be analysed from a typological perspective. A feature, a system or a construction can be compared across languages, so as to establish the limits of cross-linguistic variation and suggest possible interrelations with other properties of a language. In this respect, linguistic typology constitutes the core of linguistics as a discipline. A typologically informed analysis allows us to determine what is to be expected in a language, what is typologically plausible and what is unusual and warrants further study.

Comparing isolated entities without taking account of the whole system is unhelpful and uninformative - for instance, comparing the occurrence of an unrounded central close vowel phoneme/i/ without the phonological system in general, or looking at the realization of a visual evidential, across languages, without paying attention to the evidentiality system (grammaticalized marking of information source) in each language to be compared. The proper method is to compare complete vowel systems, or complete systems of evidentials. The role of $/ \mathrm{i} /$ within the system will vary depending on the size of the vowel system. Its phonetic realization and function in a three-vowel system will be quite different from those in a ten-vowel system. Similarly, a visual evidential in a three-term system (visual, inferred, reported) is likely to subsume a wide range of first-hand information. A visual evidential in a larger term system (for instance, visual, nonvisual, inferred, assumed, reported) is likely to be restricted to just visually acquired, or 'seen', information.

The other mode of typology relies on some phenomenon in the real world, rather than a category or a feature of the abstract system of phonology and grammar which result from a linguist's analysis. This can be called extra-language typology. A typologist may wish to look at how directionality is encoded across the languages of the world. This may involve directional verbs, directional demonstratives or special directional markers. Or there may be specific lexical items referring to direction.

If an extra-language typology describes how something in the real world - time, commands, direction, or definiteness - can be shown through a grammatical system (such as a tense system for expressing 
time, or imperative system for expressing commands), the typologist should then turn to the intra-language typology of that system. An extralanguage typology is not an end in itself. If it is to have predictive and explanatory power, it must be seen as a conduit to one or several intralanguage typological studies.

For instance, one can consider different kinds of possible information sources - vision, hearing, smell, touch, inference, assumption and verbal report. In order to come up with sensible generalizations concerning the expression of information source within languages, one should provide an in-depth analysis of grammatical systems which express these meanings, within languages.

An extra-language typology examines how something outside a language system is coded within that system. To have any scientific validity, it must be augmented by an intra-language typological study of the coding mechanism, and then the variations.

During the past decades, typological investigations have involved every domain of language. Common topics in phonological typology include syllable structure, systems of consonants, and of vowels and tones. Grammatical typology addresses the typology of word classes, and grammatical systems and categories - tense, aspect, evidentiality, gender and other noun categorization devices, case and grammatical relations, and negation. For each study - in a language and across languages - care should be taken to note how one category may interact with another. So, for instance, if a language has evidentiality, this will always apply in past tense and declarative mood but not necessarily in imperative mood and in future tense. The issue of dependencies between grammatical categories is fascinating for typological studies. So, there may be fewer distinctions in person, gender, number, tense, aspect and evidentiality under negation than in positive clauses (see Aikhenvald and Dixon 1998 for a preliminary discussion). The ways in which grammatical categories interrelate and depend upon each other may shed light on their role in human cognition, helping linguists predict what is likely, and what is not, in a particular language.

Lexical typology is particularly informative when it is viewed in interaction with grammar. Dixon (1982; 2004; 2010b: 62-114) demonstrated that if a language has even a small adjective class, it is likely to include lexemes from the semantic types of Dimension, Age, Colour, and Value. Lexical typologies may involve colour terminologies, body part terminologies and terminologies for kinship. Further fruitful topics may involve sets of verbs referring to motion; or to posture and directionality.

\subsubsection{Implications and Prediction}

Typological generalizations about any linguistic phenomena can be usefully stated as implications 'if $\mathrm{x}$, then $\mathrm{y}$ ', also referred to as 
implicational hierarchies. ${ }^{12}$ Implicational hierarchies consist of a chain of cross-linguistically confirmed generalizations which are dependent upon each other. Such a hierarchy may concern the likelihood of expression of a category, depending on type of referent, or type of construction.

Associative plurals are a special subtype of plural number which can be described as ' $\mathrm{X}$ and X's associates', e.g. Hungarian Péter-ék (Peterassociative. plural) 'Peter and his family and/or friends and/or associates', Tariana nami-sini (father's.younger.brother-Associative.pluRAL) 'father's younger brother and his associates'. ('Peter' and 'father's younger brother' are termed 'focal referents'.) In her seminal study of the phenomenon, Moravcsik (2003: 472) established the following implicational generalization which allows us to predict the marking of associative plural in a language:

(4) The choice of the focal referent for associative plurals: a cross-linguistic generalization

Proper name $>$ Definite Kin noun $>$ Definite Title noun $>$ Other Definite Human noun

'If in a language, a nominal can be a focal referent of an associative plural, so can any other nominal to its left on the scale in that language.'

This generalization - stated as an implicational hierarchy - has predictive power. We have just seen that in Tariana an associative plural can be formed on a kin noun. Following the generalization in (4), it should also be possible to form associative plural on a proper name. This is indeed the case, e.g. Tariana Marino-sini 'Mario and his associates' (see also Moravcsik, Chapter 14 of this volume).

One of the best-known implicational hierarchies in linguistics is the Nominal Hierarchy, in Diagram 1.1.

The Nominal Hierarchy helps explain why in quite a few languages, nouns operate on an absolutive-ergative principle, and personal pronouns have nominative-accusative case-marking (phenomenon known as 'split ergativity': Dixon 1994, based upon Silverstein 1976). This is the case in Dyirbal, an Australian language. In (5), 'man' is the O marked

\begin{tabular}{|c|c|c|c|c|}
\hline 1st and 2 nd person & Demonstratives & Proper & Commor & \\
\hline pronouns & 3rd person pronouns & nouns & Human Animate & Inanimate \\
\hline
\end{tabular}

Diagram 1.1 Nominal Hierarchy (Dixon 1994: 85) 
with the absolutive case, with zero realization. 'Woman' is the A (transitive subject) and is marked with the ergative case:

[bayi
NOMINAL.MARKER.ABS:MASC
[ba-1]gu-n
NOMINAL.MARKER-ERG-FEM
'The WOMan

yara $]_{O}$

man:ABS

$$
\text { yibi-ngul }]_{A} \quad \text { balga-n }
$$

woman-ERGATIVE hit-PAST

'The woman hit the man'

In (6), 'woman' is the intransitive subject (S) and is marked with the absolutive case.

$\begin{array}{lll}\text { [bala-n } & \text { yibi }]_{S} & \text { miyanda-nyu } \\ \text { NOMINAL.MARKER.ABS-FEM } & \text { woman:ABS } & \text { laugh-PAST } \\ \text { 'A woman laughed' } & & \end{array}$

If $\mathrm{A}, \mathrm{S}$ and $\mathrm{O}$ are expressed with pronouns, the marking changes. The same form of the pronoun ' $I$ ', yaja, is used for the $S$ in the intransitive (7) and for $\mathrm{A}$ in transitive (8).

(7) gajas bani-ñu

I:NOM come-PAST

'I came (here)'

$\begin{array}{lll}\text { jaja }_{\text {A }} \text { [bayi } & \text { yara]o } & \text { balga-n } \\ \text { I:NOM NOMINAL.MARKER.ABS:MASC } & \text { man:ABS } & \text { hit-PAST } \\ \text { 'I hit a man' } & & \end{array}$

In (9), a different form of the pronoun ' $\mathrm{I}$ ' is used for an O. This is an accusative form:

$$
\begin{array}{lll}
\text { payguna }_{O} \text { [ba-ngu-n } & \text { yibi-ngu }]_{A} & \text { balga-n } \\
\text { I:ACC NOMINAL.MARKER-ERG-FEM } & \text { woman-ERG } & \text { hit-pAST } \\
\text { 'A woman hit me' } & &
\end{array}
$$

The principle behind split ergative marking based on the meaning of a noun phrase reflects a general principle: a participant in an unusual role may acquire special marking, and a participant in an expected role does not have to. First and second persons singular, 'I' and 'you', are the quintessential A (the 'agent', the 'perceiver', the 'donor' and so on). 'I' and 'you' are more likely to appear as A than as O. When they do appear in $\mathrm{O}$ function, they will be marked. Next most likely A are demonstratives and third person pronouns. Human, animate and inanimate nouns are less likely to be 'A'. Many verbs typically have a human noun in their A function (e.g. 'think', 'believe', 'tell'); for others, A tends to be human or animate ('bite', 'strike', 'see', 'hear'). There is more variety with regard to $O$. An inanimate noun can be $O$ of most verbs.

The Nominal Hierarchy reflects our expectations as to which participants are more likely to appear in $\mathrm{A}$ than in O function. Participants at the left end of this hierarchy are more likely to be in A function and have 
agentive properties. Those at the right end are more likely to be in $\mathrm{O}$ or $S$ function; they can be conceived of as less agentive and less A-like. In Dixon's (1994: 85) words,

it is plainly most natural and economical to 'mark' a participant when it is in an unaccustomed role. That is, we would expect that a case-marking language might provide morphological marking of an NP from the righthand side of the hierarchy when it is in A function, and of an NP from the leftmost end when in $\mathrm{O}$ function (as an alternative to providing ergative marking for all A NPs, of whatever semantic type, or accusative marking for all O NPs).

The Nominal Hierarchy has explanatory power and also correlates with typical functions of nominals with different semantic features. It has also proved useful in other areas of language. In his pioneering work, Smith-Stark (1974) demonstrated its applicability to the expression of number: it is more likely that humans and animates will be overtly marked for number than inanimates (further work on this was done by Corbett 2000).

A well-known implication hierarchy in lexical typology concerns colour terminology in the world's languages. This was originally formulated by Berlin and Kay (1969: 5), as in Diagram 1.2.

This implicational hierarchy makes the following prediction: the presence of a term on the right implies the existence of all those to the left. So, a language with a basic term for 'blue' will be expected to have basic terms for green, yellow, red, white and black. The hierarchy is concerned with 'basic' colours (defined by Berlin and Kay 1969, and then refined in later studies). ${ }^{13}$

Implicational statements are formulated on the basis of language data. Once justified, they offer useful insights into the grammar of individual languages and provide an important investigative tool. A statistical analysis of a large corpus of Modern Russian showed that terms for 'black' and 'white' (the two foremost 'basic' colours) are the most frequent (Corbett 2011: 201-2). The three most basic colour terms in English - 'white', 'black' and 'red' - stand apart in that they can take the derivational suffix en as in whiten, blacken and redden.

This takes us to the next topic: the relations between linguistic typology and language analysis, in terms of its empirical base.

\begin{tabular}{|c|c|c|c|c|c|}
\hline \multirow[t]{2}{*}{ White } & & GREEN & & & PURPLE \\
\hline & $<$ RED & YELLOW & $<$ BluE & $<$ Brown & $\begin{array}{l}\text { PINK } \\
\text { ORANGE } \\
\text { GREY }\end{array}$ \\
\hline
\end{tabular}

Diagram 1.2 The colour terminology hierarchy originally suggested by Berlin and Kay (1969) 


\subsection{Linguistic Typology and Language Analysis}

\subsubsection{Inductive Nature of Typological Generalizations}

Typological research expected to produce substantive and meaningful generalizations about languages has to be based on the analysis of languages themselves. That is, its foundations are bound to be inductive. This resonates with Bloomfield's statement (1933: 20):

The only useful generalizations about language are inductive generalizations. Features which we think ought to be universal may be absent from the very next language that becomes accessible ... The fact that some features are widespread is worthy of notice and calls for an explanation; when we have adequate data about many languages, we shall have to return to the problem of general grammar and to explain these similarities and divergences, but this study, when it comes, will not be speculative but inductive.

Typology and language analysis feed into each other. In order to come up with sensible cross-linguistic generalization to be borne out by facts of languages, a typologist needs to rely on good-quality comprehensive reference grammars. The converse is also true. Detailed reference grammars of previously undescribed languages alert typologists to new phenomena and offer materials for new typological generalizations.

In a 1997 paper, DeLancey offered the first cross-linguistic snapshot of mirativity - a category whose main meaning is 'surprise' and 'unprepared mind'. Individual scholars of numerous languages had been aware of the existence of such a phenomenon. A similar range of mirative meanings (there termed 'admirative') occurs in a grammar of Albanian written in French by Dozon (1879: 226-7) (see Friedman 2003: 192-3, 213 , and 2012 for the history, and the meanings of the term). A verb form with 'admirative' meaning was described in grammars of north-east Caucasian languages (e.g. Kibrik 1977, 1994). Many grammars of Quechuan languages also described a verb form with a major meaning of 'sudden realization or awareness' and 'surprise' (also known as 'sudden discovery tense': see Adelaar 1977, 2013; Adelaar with Muysken 2004).

Having a cross-linguistic overview of a mirative as more than one isolated exotic curiosity alerted grammarians across the world to its existence. The term 'mirative' and the notion 'mirativity' have gained currency over the past fifteen years, and new types of mirative systems (distinct from tense, aspect, modality and evidentiality) keep being discovered (see summaries in Aikhenvald 2012; DeLancey 2012).

Along similar lines, Nordlinger and Sadler's (2004) cross-linguistic study of nominal tense alerted grammarians to this category. More and more grammars turn their attention to it than previously. Having a special set of 'tenses' on nominals is no longer an exotic feature. 
Kuteva's (1998) investigation of a poorly known cross-linguistic category 'action nearly averted' put the category 'on the map' (see also Overall, Chapter 15 of this volume). Thanks to these findings, our reference grammars are becoming fuller and more comprehensive - and our understanding of the limits of linguistic variation deepens.

The discipline of linguistic typology must rest upon firm empirical foundations. We now turn to the factual basis for typological hypotheses and generalizations.

\subsubsection{The Basis for Typological Investigation}

A typological study can vary in terms of its scope. It can range over a limited set of languages - all in one geographical region or all in one genetic family - or over all human languages. For typological generalizations and the typological classification to be significant, there should be a fair number of languages in the population considered - more than just a handful.

When a typological study aims to cover a large number of languages, potential problems arise. Perhaps as many as 4,000 languages are currently spoken or were recently spoken across the world. However, good and reliable reference grammars are available for only a fraction of these. The best way of getting as full a view of languages as possible is to try and access as many reliable sources as one can. The many partial and defective grammars are to be avoided in any typological research. And it is not the case that a newer source will necessarily be better, or more comprehensive than, an earlier one. ${ }^{14}$

Some typologists find it appropriate to limit themselves to an artificially constructed and limited sample. For instance, Bybee, Perkins and Pagliuca's (1994) survey of tense, aspect and modality in the languages of the world was based on a meagre sample of ninety-four languages from a limited set of genetic groupings, many of them not substantiated (such as 'Andean-Equatorial', 'Jê-Pano-Carib' and 'Indo-Pacific'). The grammars chosen, on a random basis, included numerous flawed and incomplete sources (see Dixon 2010a: 259-61, for further critique of sampling methodologies). ${ }^{15}$

It is useful to distinguish two approaches to typological study of grammatical categories and patterns. These can be referred to as Approach A and Approach B.

Approach A involves the following:

a. Working with primary sources. If some useful-looking information is discerned in a secondary source, this must always be checked back in the appropriate primary source. If no primary source is provided, the information in the secondary source cannot be taken account of.

b. Building typological generalizations on an inductive basis. 
c. Searching out and using all reliable sources which relate to the topic under investigation. This will involve doing an initial survey of all languages of the world, and then homing in on those groups of languages where the topic under investigation is most manifested.

d. For every topic of investigation, taking account of social, areal and historical considerations, thus incorporating linguistic history into the patterns of distribution for the phenomenon. For instance, an openended typology of nasalization will pay attention to the fact that nasalization is a prominent areal feature of many parts of Amazonia but does not feature overmuch in European languages.

e. Attempting at an explanation of the nature and distribution of the phenomenon under investigation - language internal, historical and maybe also sociocultural.

It is typically the case that the proponents of Approach A have themselves undertaken intensive linguistic fieldwork and written grammars of previously undescribed languages. They thus have the experience which enables them to evaluate the worth of grammars.

Approach B typically involves the following:

a. Making copious use of secondary sources without attempting in all cases to check that they have quoted correctly from primary sources.

b. Sometimes working inductively, but sometimes deductively. The latter course involves putting forward an a priori hypothesis and then looking at just a few selected languages to see whether it can be upheld.

c. Consulting just a 'sample' of languages, without regard for whether they may be representative for the topic of investigation or whether the materials available are reliable.

d. Focusing on linguistic data as an end in itself, without paying too much attention to the social and areal contexts and historical origin.

Studies and surveys following Approach B - typically undertaken by those who have not undertaken original fieldwork themselves - run the risk of misinterpreting original sources. Those who aim at valid typological generalizations are better off avoiding such secondary investigations.

A typologist needs to exercise care in stating what is common and what is infrequent across languages. Suppletive classificatory verbs are a common feature in Athabaskan languages, and also in sign languages but uncommon in languages of most other areas. Haude (2010) presents nominal tense in Movima, an isolate from Bolivian Amazonia, as a typologically rare feature. This would be exotic if compared with IndoEuropean languages. However, Amazonian and Australian languages offer numerous examples of this phenomenon, enough to build a typology (see Nordlinger and Sadler 2004; Tonhauser 2007, 2008; summary in Aikhenvald 2012: 158-62). We will not be able to state the frequency of 
any phenomenon with full assurance until most languages of the world have been properly investigated.

The idea has spread that using sampling techniques, and quantified correlations and chi-square tests and the like, makes linguistics 'scientific'. But what is needed, at the present time, is not quantitative comparison of superficial bits of surface structure, but rather qualitative study, providing careful and fine-grained analysis of the underlying structures of the multitude of languages which are still spoken and are in need of comprehensive documentation.

New sources shed new light on the distribution of particular categories and constructions cross-linguistically. Evidentiality (viewed as grammaticalized information source) was a rare bird in African languages. Recent comprehensive descriptions have revealed its existence in a number of groups (see König 2013 on Khoisan; Storch 2013 on Luwo; and a brief survey in Aikhenvald 2014).

What, then, is the optimal procedure for delimiting a database in typological enquiry? Is any type of sampling appropriate? The answer is: 'not really'. Instead, one should carry out an extensive survey, and then home in on intensive studies. For instance, when Alexandra Aikhenvald began working on a cross-linguistic study of evidentiality, her first step was to survey languages across every linguistic area and genetic family. The category is missing from certain regions, spottily represented in some, rampant in others. Having identified critical areas, she then embarked on a detailed examination of all the welldescribed languages there. She also looked at poorer grammars of some of the languages which might be expected to include an evidentiality system, seeing if she could spy any symptomatic features and, where possible, corresponded with authors of the grammars. Finally, as the result of six or seven years of fairly intensive study, in 2004 she published a 479-page monograph called Evidentiality which covered as much on the phenomenon as was available at the time. ${ }^{16}$

One vitally important point which has been mentioned before but deserves emphasis is that not everything which has appeared in print been written down - is equally good. When embarking on a comparative study of the indigenous languages of the Americas, Peter S. Duponceau - in 1819 - set out his method of working:

I left no book or manuscript unconsulted that came within my reach; but I examined the assertions of each writer with a critical eye, fully determined in no case to swear on the word of a master. I tried to discover the sources from which my authors had derived their knowledge; the opportunities which they had of acquiring it; the time which they had spent among the Indians, or in the study of their languages; the degree of attention which they had bestowed upon it, and the powers of mind by which they had been enabled to take a just and an accurate view of their subject. Finally, I rejected every thing that came in the shape of 
mere assertion, and paid attention only to those specimens of the different idioms in which their grammatical structure was sufficiently exhibited.

Such a comprehensive and critical approach will ensure the validity of typological generalizations. The time that will go into such work will be time well spent.

A word on the methodology and theoretical underpinnings of linguistic typology. Throughout the past two centuries, the bulk of inductive generalizations about the world's languages were cast in an analytic framework based on an in-depth description of linguistic facts not constrained by any ad hoc formal models. This framework has been recently given the name of 'basic linguistic theory' (see Dixon 2010a, 2010b, 2012). In this framework, every analytic decision has to be proved. It is oriented towards expanding our view of structural diversity. This is the perspective taken throughout this volume. ${ }^{17}$

\subsubsection{Prerequisties for Consistent Analysis}

The first and major prerequisite for a typological investigation is reliable sources. The quality of our typologies depends on the quality of the sources we have available, and it is indeed hard to compare a phenomenon in two languages or one which has a full comprehensive grammar with another that has just a small, barely informative sketch. This is a recurrent problem, highlighted by many authors of this volume.

Comprehensive reference grammars based on extensive fieldwork constitute an ideal solid basis for typological work (a list of examples of such grammars is in Dixon 2010a: 81-5). One needs to avoid partial descriptions based on limited sources for a language which is still well spoken. Partial and limited analyses based on field methods courses must be excluded from typological analysis. ${ }^{18} \mathrm{~A}$ major commandment for a typologist - just as for any scholar - is to always go back to original sources (see Dixon 2010a: 64-6).

A further prerequisite for a coherent typological study is consistent and compatible analyses of languages compared. One can only sensibly compare things described in similar terms. Compatible analyses of languages are a sine qua non for typological comparison. A typologist examining grammars of a number of languages should not uncritically reproduce descriptions.

Different authors may use terms differently. Take the term 'serial verb construction'. This is generally applied to a sequence of verbs without any overt marking functioning as one predicate (see summary and references in Aikhenvald 2006). Scholars of Tupí-Guaraní languages (e.g. Jensen 1999) use this term to describe sequences of verbs, one of which is cast in a verb form marked for subordination (and termed 'gerund'). These structures, 
no matter what they are called, should not be considered in a typology of serial verb constructions.

Descriptions of South-East Asian languages use the term 'classifier' to refer to a numeral classifier. In the Athabaskan linguistic traditions, 'classifier' is a grammatical voice marker on verbs. What Athabaskanists call 'gender' corresponds to verbal prefixes which classify a noun phrase in terms of its shape and form; this is very different from the way 'gender' is used in familiar Indo-European languages (see Aikhenvald, Chapter 12 of this volume).

The term 'passive' is used in a number of meanings. A survey of passives states: "The analysis of the various constructions referred to in the literature as "passive" leads to the conclusion that there is not even one single property which all these constructions have in common' (Siewierska 1984: 1). This shows that a typologist must take great care in assessing what is described as a passive construction in each grammar under consideration. (For a comprehensive typology of passives and other valency reducing derivations, see Dixon 2010a: 166-8; 2012: 197-238).

When embarking on a typological investigation of category $\mathrm{X}$, one must first of all adopt a working definition of 'what X is' and the types of criteria for recognizing it in a given language. Then, for each language which is studied, the available grammar(s) must be carefully assessed to see if what is there called ' $\mathrm{X}$ ' accords to the definition and criteria (or, perhaps, whether something which is given a different label in the grammar does so). In some languages, what are called 'passive' will not satisfy the criteria and so should be excluded from the typological study.

A careful approach is particularly important in dealing with categories which are comparatively new in linguistic typology and may not be familiar to many general linguists. The category of 'frustrative' is a case in point. Simon Overall looks at the meanings of morphemes called 'frustrative' (and other morphemes, with similar overtones) (Chapter 15 of this volume) and provides a working definition which allows him to define the meanings and the uses of this hitherto marginalized category.

It would be a mistake to look up the index at the end of a grammar, see that, say, 'passives' or 'reciprocals' are discussed on pages 332-5 and then just read these four pages. As Antoine Meillet (1926: 16) put it, 'une langue constitue un système complexe de moyens d'expression, système où tout se tient' ('a language makes up a complex system of means of expression, a system in which everything holds together'). Scientific linguists who produce comprehensive grammars of languages naturally follow this tenet. Those who look at isolated bits of language, for some particular issue, go against this fundamental principle of systematic analysis. Analytic decisions about passives are likely to depend on or interrelate 
with other kinds of analytic decisions, in various parts of the grammar (for example, concerning number and types of arguments). Proper procedure is to study the whole grammar in outline, to understand the context for this short discussion of passives, and then see how this links up with treatment of transitivity, other syntactic derivations which affect valency, discourse structure and the like.

In summary, one should undertake typological study of some aspect of the underlying organization of grammar, rather than of its surface realization solely guided by the use of a term. And one should carefully consider the analysis of this feature provided by each grammar that is included in the survey. In an ideal world, writers of grammars would all employ similar criteria and make analytic decisions on a similar set of criteria. But nothing is ideal.

A word on typology and reference grammars. Grammatical analysis and typological generalizations interact. A comprehensive reference grammar will be incomplete without a general typological profile of the language.

This highlights features that give the grammar its distinctive character, cast within a general perspective of cross-linguistic typological investigation. A typological profile needs to address parameters in morphological typology, mentioning - among many other topics:

- whether the language is prefixing, or suffixing, or both, and how many prefix and suffix positions are typically encountered; whether there are infixes;

- whether the language is isolating, or fusional, or agglutinating;

- whether the language is analytic or synthetic;

- whether the language is absolutive-ergative, or nominative-accusative (or combine both patterns);

- whether there are genders, or classifiers of any types, or both (more on this in Aikhenvald 2015: 30-2).

Typological profiles of languages are based on a set of synchronically attested features. However, in order to expand its explanatory powers, typology needs to go beyond a purely synchronic approach. We now turn to the relationships between typology, linguistic history and language contact.

\subsection{Typology, History and Contact}

Linguistic typology aims at establishing parameters for cross-linguistic variation at a particular point in time, without any consideration for language history, or contact between languages. That is, typology is synchronically oriented. Typological similarities have to be kept separate from shared features due to genetic inheritance, and changes induced by 
language contact. Stating that languages are 'related' because they share a structural typological feature is nonsensical. ${ }^{19}$

However, typological research can branch out into historical linguistics and the investigation of diachronic language change. It can turn out to be crucial in setting limits for the potential of what one can expect in any language, including a putative proto-language.

What we learn through linguistic typology helps uncover what is likely, what is possible and what is unlikely in a human language. Linguistic typology sets a 'limit' to what a human language does. This limit, captured by the notion of 'typological plausibility', helps evaluate the likelihood of a linguistic reconstruction and the putative paths of linguistic change. We can thus work on a diachronic typology and a typology of historical processes going beyond the here-and-now of synchronic typology.

The 'typological plausibility principle' guides and limits what we should logically be able to reconstruct in our endeavour to recover the diachrony of a group of related languages. Typology can be used 'to justify the possibility of a given reconstruction by uncovering analogues in attested languages'. It can also provide 'an argument against a particular reconstruction by showing that there are either principles or strong empirical arguments that the reconstruction reflects a very unlikely language type, although the strength of such arguments will always depend on the level of development of typology' (Comrie 1993: 95). A further connection between typology and historical linguistics lies in establishing universals and universal tendencies in language change, including development of individual patterns (e.g. tones) and principles of grammaticalization (see also Hopper 1987; Hock 1991, 2010). Establishing limits to typological variation allows us to formulate predictions as to the ways in which a language might develop.

Similarities in the ways languages develop offer an additional link between historical investigation and typological research. Genetically related languages 'will pass through the same or strikingly similar phases': this 'parallelism in drift' (Sapir 1921: 171-2) accounts for additional similarities between related languages, even for those 'long disconnected'. Parallelism in drift may account for shared typological features of genetically related languages.

Typology as investigation of cross-linguistic variation is - ideally independent of how languages in geographical proximity influence each other in contact situations. In practice, an informed study of crosslinguistic variation and its spread helps delineate linguistic areas and assign the weight of features (see Luraghi, Chapter 4 of this volume).

Each language community (save for a very few confined to a distant island or an inaccessible mountain valley) is in contact with other communities, speaking different dialects or languages. The communities will interact, through trade, shared festivals and rituals, inter-marriage and 
maybe wars. Through all this, their languages also interact. They may come to sound more similar. They may borrow some vocabulary, and some structural and organizational features of the languages may converge, often resulting in a constellation of structural features which can be referred to as 'typological profile', or a 'type' of a linguistic area (see Enfield, Chapter 19, for languages of mainland Southeast Asia; Dixon, Chapter 20, for the Australian linguistic area; and Adelaar, Chapter 21, for Quechuan and Aymaran languages).

Thus, for instance, languages spoken in the Balkans share such features as (i) lack of the infinitive, (ii) syncretism of dative and genitive markers, (iii) postposed definite article and (iv) two-term evidentiality systems. This is subsumed under a term 'Balkan type'. A subfield of areal typology deals with linguistic features which spread and develop as a result of language contact. Areal typological studies are crucial for understanding the dynamics of possible language contact and language history (see, for instance, Aikhenvald and Dixon 1998, and further papers in Ramat 1998).

Typological profiles of linguistic families and linguistic areas constitute a fruitful avenue for examination, as they allow us to catch a glimpse of linguistic, and cognitive, diversity, and its limits. In addition, typological tendencies characteristic of a family can suggest the ways in which individual languages may change. Typological tendencies - and features - of an area may help us understand the dynamics of language contact, and contact-induced change.

The family or the area may be characterized by special features, such as possessive classifiers in Oceanic languages or multiple noun classes in Bantu languages. It is important to point out the parameters of variation within the family, with regard to any distinct typological feature. For instance, most Arawak languages of South America have two genders; however, Palikur has three genders, and Amuesha, Waurá and Terêna have lost gender distinctions altogether.

A set of synchronically established grammatical features found in a linguistic family or its subgroup can be referred to as its 'type'. Austronesian languages of the Philippines (and also some languages of Taiwan) have cross-linguistically unusual alternative transitive constructions whereby one argument is placed in 'focus'. This is shown by affix(es) on the verb indicating the function of the focused argument (which can be transitive subject, object or recipient, or an oblique (instrument or location). Having a system of such verbal 'focuses' or 'voices' is often referred to as the Philippine type. ${ }^{20}$

A feature or a property may be found in just one subgroup of a family. Take relational classifiers - a special class of morphemes used in constructions with alienable possession which characterize the possessed in terms of how it is handled (for instance, whether it can be eaten or drunk). By and large, these are found only in the Oceanic subgroup of 
the Austronesian family (see Guérin, Chapter 29 of this volume). They can be referred to as an 'Oceanic-type' feature. Along similar lines, suppletive classificatory verbs are usually associated with Athabaskan languages where they are most prominent and best known. Classificatory postural verbs are a feature of the New Guinea Highlands (Aikhenvald, Chapter 12 of this volume).

Areal and historical studies help provide the answer to the question why the languages are the way they are. This is one of the goals of linguistic typology.

Now a word of caution. In order for a typology to be reliable, and relevant for historical and areal investigations, a scholar should be careful in establishing genetic affiliation of languages. Languages of the world are divided into proven families - such as Indo-European, Uralic, Dravidian, Tai-Kadai, Algonquian, Athabaskan, Arawak, Panoan, Carib, Tupí, to name just a few. Based on occasional shared formal similarities and shared typological features, speculative genetic groupings have been suggested (such as Indo-Pacific, Ge-Pano-Carib, Macro-Equatorial, Amerind, Arawakan, Pama-Nyungan, Nostratic, etc.). Putative longdistance groupings - unless proved - remain, in Matthews' (2007: 268) words, 'the kind of hypothesis one believes to the extent that one believes in that kind of hypothesis'. To make a typology a scientific enterprise, such science-fictional units need to be avoided. ${ }^{21}$

\subsection{About This Volume}

This volume offers a state-of-the art view of major issues within presentday linguistic typology in its varied guises, with equal attention to (a) universal tendencies across languages in various domains, (b) typological variation within individual categories and (c) patterns of linguistic diversity, across a selection of language families and groups from across the world.

The volume consists of three parts. Part I, 'Domains of Linguistic Typology', comprises nine chapters. The first five chapters cover a subfield of linguistic typology and its interaction with other fields or areas within the discipline of linguistics: Harry van der Hulst (Chapter 2) offers a reappraisal of typological research in phonology. Thomas E. Payne (Chapter 3 ) addresses various issues in morphological typology, including its history and development over the past centuries. Silvia Luraghi (Chapter 4) discusses the relationship between typology, historical and comparative linguistics, and language contact and change. Grammaticalization is a major historical and synchronic mechanism of creation and development of grammatical forms. Sociolinguistic typology is a relatively recent arrival on the linguistic scene. This is concerned with establishing types of social structures and the ways in which 
these are reflected in linguistic practices, including language attitudes, language use and sociolinguistically based variation. In Chapter 5, Peter Trudgill - in many ways the founder of the discipline - offers a discussion of sociolinguistic typology with regard to interdependencies between social structures and linguistic complexity, demonstrating the explanatory power of such correlations. In Chapter 6 , Heiko Narrog discusses the ways in which tendencies and generalizations in linguistic typology interact with principles of grammaticalization.

The last four chapters in Part I are concerned with typological properties of a selection of different linguistic systems rarely addressed in the typological literature. Sign languages occupy a different modality, with different means of expression from spoken languages. Only by investigating both spoken and signed languages can we come to understand the full range of possibilities of human language structures. Typological studies of sign languages is a newly emerging field which is likely to open new paths into cross-linguistic studies and linguistic diversity beyond the spoken word. Ulrike Zeshan can be rightfully considered the pioneer of the field (e.g. Zeshan 2004). Much of modern-day typology has focused on the properties of spoken languages. To amend this historical bias, Ulrike Zeshan and Nick Palfreyman (Chapter 7) offer an incisive typological sketch of sign languages and some of the differences and commonalities with spoken languages.

Mixed, or intertwined languages - a number of which arose as a result of conscious language manipulation - are a fruitful and yet largely unexplored field of typological research. Typological features of mixed languages are the topic of Chapter 8, by Peter Bakker. In terms of their origins and functions, Creole languages are a special kind: they arose as a consequence of people of several different linguistic backgrounds having to communicate with each other and developing a common, often simplified, linguistic variety. Creole languages have a distinct set of structural features, and it is a fascinating task for a typologist to identify them and correlate them with the donor languages and processes involved. Typological features of Creole languages are the topic of Chapter 9, by Aymeric Daval-Markussen and Peter Bakker.

What are the limits of human linguistic creativity? Secret languages - used for ritual communication or to exclude an unwanted group - and linguistic taboos involve manipulating linguistic structures in comparable ways; the typological principles behind these and their place within language structure are addressed by Anne Storch, in Chapter 10.

Part II, 'Typology of Grammatical Categories', comprises eight contributions, each dealing with typological investigation of one core aspect of grammatical structure. In Chapter 11, David Beck offers 
a comprehensive typology of morphological means (in some ways complementing Chapter 3, on morphological typology). In Chapter 12, Alexandra Y. Aikhenvald offers a typology of noun categorization devices (which cover genders, noun classes and classifiers of different kinds). The typology of negation - a universal category found in every human language - is the topic of Matti Miestamo's Chapter 13. Edith A. Moravcsik offers a comprehensive reappraisal of expression and meanings of number and quantity across the world's languages in Chapter 14.

Some categories within Part II are relatively recent arrivals on the linguistic scene. The verbal category of frustrative is a prominent feature of many languages of Lowland Amazonia. It expresses nonrealization of an expected outcome - and also the frustration of the speaker. In Chapter 15, Simon E. Overall offers a typology of frustrative marking, its semantics and development in Amazonian languages, as a first step towards a comprehensive outline of this fascinating, and so far neglected, category.

A number of African languages in what is known as the 'Macro-Sudanic belt' have a paradigm of person markers indicating co-reference with the real or imagined author or source of secondary discourse. This has come to be known as 'logophoricity', a type of marking rarely found outside West Africa. In Chapter 16, Felix K. Ameka offers a comprehensive typological analysis of logophoricity, its meanings and expression, with special attention to the sociocultural and communication practices in West Africa which underlie logophoricity.

Switch reference - a major mechanism for keeping track of participants in discourse - is a salient feature of many languages of the world, especially in New Guinea and North and South America. Chapter 17, by John Roberts, contains a concise typological appreciation of crosslinguistically common patterns of switch reference (with special focus on the Papuan languages of New Guinea, the major expertise of the author). Chapter 18, by Eric Pederson, is somewhat different in nature and scope: it contains an up-to-date overview of approaches to the expression and analysis of the meaning of one semantic category motion events - across human languages.

We place special focus on the analysis of the world's languages within a typological perspective, thus contributing to the appreciation and providing an up-to-date statement of linguistic diversity and variation between languages. Part III, 'Typological Profiles of Language Families and Linguistic Areas', features twelve contributions, each dedicated to a typological profile of a selected linguistic area or a language family, or a subgroup. We have striven to achieve a combination of well-known and not-so-well-known areas and families, to give our readers a glimpse into the range of typological diversity across the world's languages. Each typological profile of a language family or a subgroup is synchronically 
oriented, with a mention of features reconstructible to the protolanguage.

The first three chapters address typological features of linguistic areas. In Chapter 19, N. J. Enfield presents an almost exhaustive analysis of the features of languages in the mainland Southeast Asia area. The Australian linguistic area and its linguistic traits are discussed by R. M. W. Dixon in Chapter 20. In Chapter 21, Willem F. H. Adelaar provides a comprehensive account of the major typological features of Aymaran and Quechuan languages in the Central Andean region of South America.

The remaining chapters focus on typological properties of a selection of genetically established families and subgroups. We start with North America and proceed from north to south. In Chapter 22, Michael Fortescue offers a comprehensive account of the Eskimo-Aleut language family. Keren Rice and Willem de Reuse offer a detailed, in-depth account of the Athabaskan (Dene) language family in Chapter $23 .^{22}$ An all-embracing account of the Iroquoian language family and its daunting complexities is presented in Chapter 24, by Marianne Mithun. It is hard to give justice to the linguistic diversity of Amazonia. Facts from Amazonian languages are discussed in many of the chapters in Parts I and II. Part III contains just one contribution dealing with an Amazonian group: in Chapter 25, Elena Mihas offers an in-depth account of the typological characteristics of the Kampa subgroup of Arawak languages (one of the best-established divisions within this large family, some of whose internal classification remains a matter for investigation). The Omotic language family, described in detail by Azeb Amha in Chapter 26, is part of a large Afroasiatic grouping. The genetic unity, and the status of Omotic languages as a family within Afroasiatic, was recognized later than that of its other members. The Semitic language family - the family with the longest history of attestation within Afroasiatic which boasts some of the world's earliest documented languages such as Hebrew and Akkadian - is addressed in Chapter 27, by Aaron D. Rubin. The many typologically interesting features of the Dravidian language family are the topic of Chapter 28, by Sanford Steever. Austronesian languages comprise one of the largest families of the world. Its Oceanic subgroup - consisting of about 500 languages - has numerous distinctive features examined by Valérie Guérin, in Chapter 29. The island of New Guinea is a high spot of linguistic diversity in every possible meaning of the term. Papuan languages have been discussed throughout a number of chapters in Parts I and II. Chapter 30, by Lourens de Vries, gives an in-depth account of the relatively lesser known Greater Awyu Ndumut language family of West Papua, their history and distinctive properties.

We have assembled a stellar team of authors experienced in linguistic typology, historical comparative issues and first-hand investigation of the relevant languages. Throughout the volume, the analysis is cast in 
terms of basic linguistic theory - the cumulative typological functional framework in terms of which almost all reference grammars are cast, and empirically sound generalizations - which will stand the test of time - formulated.

It would be nonsensical to think of this - or any other - volume on linguistic typology as 'the last word'. We hope that this volume will contribute to our understanding of what is common to many languages, and how human languages vary, expanding our knowledge and appreciation of the wondrous world of linguistic diversity and the surprises it has in stock.

\section{Notes}

1. Further discussion of the subject matter of linguistic typology can be found in Comrie (1988, 1989, 1991), Bazell (1958), Mallinson and Blake (1981), Daniel (2011) and Greenberg (1974), and references there.

2. See Evans and Levinson (2009), Comrie (1989) and references there on the limits of 'absolute' universals. Predictive powers of implicational universals are discussed by Corbett (2011) and especially Moravcsik (2011). Implicational universal tendencies can be stated in the form of hierarchies; more on this in $\S 1.2 .3$. See Ohala (1975) for further discussion of nasal vowels and nasality.

3. See the discussion in Aikhenvald (2000: 244-5); see Plank and Schellinger (1997) for further counterexamples. Comrie (1989: 17-23) outlines a distinction between formal and substantive universals; see an overview in Cristofaro (2011). Moravcsik (2011) offers a useful attempt at explaining linguistic universals.

4. See Aikhenvald (2006) on serial verb constructions, Smith-Stark (1974) on number marking.

5. Approaches to the notion of universals vary depending on linguists' theoretical persuasion. One extreme - which appears in Berman and Slobin (1994: 641) - is to view 'each individual language' as 'representing but one variant of a familiar and universally human pattern'. The other extreme is to foreground diversity between languages at the expense of potential universal or near-universal hypotheses (for example, by Evans and Levinson 2009, reflected in their title 'the myth of linguistic universals'). By working together with experts on individual languages and especially fieldworkers, linguistic typologists are making progress towards understanding and explaining the limits of variation between languages.

6. The term 'parameter' is used here to refer to a general characteristic of languages. Note that this term has been used in a somewhat different sense in generative formalist linguistic literature, where a parameter is understood as a specific property predicting a number of other specific 
properties. A general critique of the theory of parameters can be found in Newmeyer (1998: 350-64).

7. See Payne, Chapter 3 of this volume, for a comprehensive analysis of advances in morphological typology.

8. See Dixon (2010a: 325-8), Aikhenvald (2007) on morphological types of languages; Fortescue (forthcoming) on the notion of polysynthesis.

9. The foundations of linguistic typology as a principled study of crosslinguistic differences and similarities, and as linguistic classification based on explicit parameters were laid in the early nineteenth century. Early typologies were oriented towards classifying languages in terms of morphological complexity of words and their composition. The best-known early typology is that by Wilhelm von Humboldt (1836), based on earlier work by August Wilhelm von Schlegel (1818) and Friedrich von Schlegel (1808). An evolutionary perspective was added by Schleicher (1859). Sapir's work can be considered a further breakthrough in cross-linguistic study of languages and their classification based on structural properties (see Sapir 1921). See historical surveys in Comrie (1981), Greenberg (1974), Ramat (2011), Haase (2001a, 2001b), Morpurgo Davies (1975, 1997) and Kemmer (2003).

10. Since morphological typology and constituent order typology address the language as a whole, they are sometimes referred to as 'holistic', in contrast to typologies of structures, categories or construction types which can be called 'partial' (cf. Comrie 1991, 2001). Typology of constituent order (mislabelled as 'word order typology') has dominated the field of typology, with variable success, since the 1960 s. Further discussion can be found in Comrie (1989, 1991), Mallinson and Blake (1981), Moravcsik (2011) and Dryer (2007); see criticism in Vennemann (1974) and Hawkins (1983, 2001).

11. See also Comrie (1991: 444); Hewitt (1979: 36) for Abkhaz (glosses partially from Comrie 1991: 444).

12. See also Corbett (2011), Comrie (1989), Moravcsik (2003) on associative plural; Smith-Stark (1974) and Dixon (1994) for the Nominal Hierarchy.

13. Further refinements can be found in Kay and McDaniel (1978), Kay, Berlin and Merrifield (1991) and Kay et al. (2009); see also Uusküla and Sutrop (2010) for discussion of a possible exception. Foley (1998: 150-65) contains a useful summary. Further well-known hierarchies include the agreement hierarchy (Corbett 1979), which concerns agreement on the predicate, attribute, relative and personal pronoun; and the Accessibility Hierarchy which addresses the noun phrase positions which can be relativised (Keenan and Comrie 1977). Not every hierarchy or correlation holds out when addressed in some detail. For instance, Greenberg's (1972) general hypothesis that 'if a language has numeral classifiers it does not have obligatory number on nouns' has been proved erroneous (it holds only for languages of 
highly analytic and isolating profile) (see Aikhenvald 2000: 100-1; Nomoto 2013).

14. Anyone wanting to obtain information on the Australian language Gumbaynggirr should consult not only Eades (1979) but also a fuller account in Smythe (1948/9). Along similar lines, Morse and Maxwell's (1999) grammar of Kubeo, a Tucanoan language, is perhaps not ideal, but it covers many more topics in much more depth than the more recent one, by Chacon (2012).

15. A further ambitious, and yet disappointing, attempt at offering a typological picture of a variety of grammatical and other categories across the world is The world atlas of language structures (WALS) (Haspelmath et al. 2005). This source suffers from errors in quoting and interpreting data sources, variable coverage for different parameters and idiosyncratic criteria (see criticism in Schultze 2007; Bright 2007; Plank 2009 (and other papers in the same issue); Dixon 2012: 87, 290, 338, 462-3; Dixon 2010b: 258).

16. As new systems and descriptions become available, this work goes on; major outcomes are summarized in Aikhenvald, The Oxford handbook of evidentiality (forthcoming).

17. Deduction-based investigations, such as the generative theory of universal grammar, have been of limited use to our understanding of cross-linguistic variation of languages, and their potential; see Kemmer (2003: 312) and Haider (2001) on the limited contribution to typological research made by formal theories. These approaches are usually based on data from relatively few languages, focusing on grammaticality judgements (rather than language use); they are often oriented towards English and tend to seek explanation for the hypotheses in theory-specific structural properties which are assumed to be common to all languages.

18. A typologist ought to be particularly wary of studies based on translations, limited corpora and especially field methods courses. Kara is an Oceanic language spoken by a few thousand people in New Ireland. There is no comprehensive grammar of Kara as yet. Dryer (2013) is a 'grammar' of Kara based on the analysis of the translation of the New Testament into the language. This source can perhaps be used for translation studies, but should not be used for typological comparison (because it does not reflect the language as it is spoken or used by the community). Similarly, Bowern's (2011) description of Titan, a major indigenous language of the Manus province of Papua New Guinea, is based on the analysis of texts collected by missionaries. This is not an appropriate source for any comparative studies, because of its limited scope. Loughnane's $(2003,2005)$ study of Golin is based on a field methods class and cannot be used in typological research (a scholar interested in related languages will be better off perusing a comprehensive grammar of Dom, by Tida 2006). Similarly, Lawler's 
(1988) study of passives in Acenhese is compromised by the limited data obtained during a field methods course. Interested scholars ought to use Durie's $(1985,1988)$ work.

19. See, for instance, Greenberg (1974), Dixon (1997), Hock (1991), among other sources, on the independence of typological and genetic classifications of languages.

20. See Blust (2008) for a Pan-Austronesian perspective on 'Philippine-type' focus or 'voice' focus; and further references and analysis in Dixon and Aikhenvald (1997).

21. Typologists - or any linguistic scholars - worth their salt will also base their statements on genetic affiliation of languages on the opinions of respected specialists in the field - that is, IndoEuropeanists on Indo-European, Uralicists on Uralic and so forth. Glottolog (www.glottolog.org, Hammarström et al. 2015) is a newly established resource which is highly problematic. The first-named co-author of this chapter whose major expertise and publishing record lies in Arawak (also known as Maipuran) languages and other languages of South America was overwhelmed with the sheer number of mistakes and misinterpretations in the fanciful classification of languages of this family, indiscriminate use of linguistic references of mixed quality. There is, in addition, a general disregard for specialist scholarly achievements in the field and the work of experts. Numerous mistakes and misinterpretations have been found by the second co-author, in sections on Australian languages. Until such time as these issues are addressed, Glottolog will remain a source to be used with extreme caution. A good general source on the world's languages is Brown and Ogilvie (2009).

22. The name of the language family under discussion is spelled in several ways: Athabaskan, Athapaskan, and Athabascan. Recently, the term 'Dene' (the word for 'person' in many of the languages) has been used for the name of the family.

\section{References}

Adelaar, Willem F. H. 1977. Tarma Quechua: Grammar, texts, dictionary. Lisse: The Peter de Ridder Press.

2013. A Quechuan mirative? In Alexandra Y. Aikhenvald and Anne Storch (eds.), Perception and cognition in language and culture, pp. 95-110. Leiden: Brill.

Adelaar, Willem F. H. with Pieter Muysken. 2004. The languages of the Andes. Cambridge University Press.

Aikhenvald, Alexandra Y. 2000. Classifiers: A typology of noun categorization devices. Oxford University Press.

2004. Evidentiality. Oxford University Press. 
2006. Serial verb constructions in a typological perspective. In Alexandra Y. Aikhenvald and R. M. W. Dixon (eds.), Serial verb constructions: A cross-linguistic typology, pp. 1-87. Oxford University Press. 2007. Typological dimensions in word formation. In Timothy Shopen (ed.), Language typology and syntactic description, Vol. III, pp. 1-65. Cambridge University Press.

2012. The essence of mirativity. Linguistic Typology 16(3): 435-85.

2014. The grammar of knowledge in typological perspective. In Alexandra Y. Aikhenvald and R. M. W. Dixon (eds.), The grammar of knowledge: A cross-linguistic typology, pp. 1-51. Oxford University Press.

2015. The art of grammar. Oxford University Press.

(ed.). Forthcoming. The Oxford handbook of evidentiality. Oxford University Press.

Aikhenvald, Alexandra Y. and R. M. W. Dixon. 1998. Evidentials and areal typology: A case study from Amazonia. Language Sciences: Areal typology (special issue, ed. Paulo Ramat) 20: 241-57.

Bazell, C. E. 1958. Linguistic typology. An inaugural lecture delivered on 26 February 1958. School of Oriental and African Studies, University of London.

Berlin, Brent and Paul Kay. 1969. Basic color terms: Their universality and evolution. Los Angeles: University of California Press.

Berman, Ruth A. and Dan I. Slobin. 1994. Relating events in narrative: A crosslinguistic developmental study. Hillsdale, NJ: Lawrence Erlbaum.

Bloomfield, Leonard. 1933. Language. New York: Holt.

Blust, Robert. 2008. Austronesian languages. Canberra: Pacific Linguistics.

Bowern, Claire. 2011. Sivisa Titan: Sketch grammar, texts, vacabulary based on material collected by P. Josef Meier and Po Minis. Honolulu: University of Hawai'i Press.

Bright, William. 2007. Review of The world atlas of language structures, edited by Martin Haspelmath, Matthew S. Dryer, David Gil and Bernard Comrie. International Journal of American Linguistics 73: 241-54.

Bybee, Joan L., Revere D. Perkins and William Pagliuca. 1994. The evolution of grammar: Tense, aspect, and modality in the languages of the world. University of Chicago Press.

Brown, Keith and Sarah Ogilvie (eds.). 2009. Concise encyclopedia of languages of the world. Oxford: Elsevier.

Chacon, Thiago. 2012. The phonology and morphology of Kubeo: The documentation, theory, and description of an Amazonian language. PhD dissertation, University of Hawai'i, Manoa.

Comrie, Bernard. 1981. Language universals and linguistic typology. University of Chicago Press.

1988. Linguistic typology. Annual Review of Anthropology 17: 145-59. 
1989. Language universals and linguistic typology: Syntax and morphology, 2nd revised edn. Oxford: Blackwell and University of Chicago Press.

1990. Holistic versus partial typologies. In Werner Bahner, Joachim Schildt and Dieter Viehweger (eds.), Proceedings of the Fourteenth International Congress of Linguists, Vol. I, pp. 139-48. Berlin: Akademie-Verlag.

1993. Typology and reconstruction. In Charles Jones (ed.), Historical linguistics: Problems and perspectives, pp. 74-97. London: Longman.

2001. Different views of language typology. In Martin Haspelmath, Ekkehard König, Wulf Oesterreicher and Wolfgang Raible (eds.), Language typology and language universals: An international handbook, Vol. I, pp. 24-39. Berlin: Walter de Gruyter.

Corbett, Greville G. 1979. The agreement hierarchy. Journal of Linguistics 15: 203-24.

2000. Number. Cambridge University Press.

2011. Implicational hierarchies. In Jae Jung Song (ed.), The Oxford handbook of linguistic typology, pp. 190-205. Oxford University Press.

Cristofaro, Sonia. 2011. Language universals and linguistic knowledge. In Jae Jung Song (ed.), The Oxford handbook of linguistic typology, pp. 227-79. Oxford University Press.

Daniel, Michael. 2011. Linguistic typology and the study of language. In Jae Jung Song (ed.), The Oxford handbook of linguistic typology, pp. 43-68. Oxford University Press.

DeLancey, Scott. 1997. Mirativity: The grammatical marking of unexpected information. Linguistic Typology 1: 33-52.

2012. Still mirative after all these years. Linguistic Typology 16: 529-64.

Dixon, R. M. W. 1982. Where have all the adjectives gone? And other essays in semantics and syntax. Berlin: Mouton.

1994. Ergativity. Cambridge University Press.

1997. The rise and fall of languages. Cambridge University Press.

2004. Adjective classes in typological perspective. In R. M. W. Dixon and Alexandra Y. Aikhenvald (eds.), Adjective classes: A cross-linguistic typology, pp. 1-49. Oxford University Press.

2010a. Basic linguistic theory, Vol. I: Methodology. Oxford University Press.

2010b. Basic linguistic theory, Vol. II: Grammatical topics. Oxford University Press.

2012. Basic linguistic theory, Vol. III: Further grammatical topics. Oxford University Press.

Dixon, R. M. W. and Alexandra Y. Aikhenvald. 1997. A typology of argument-determined constructions. In Joan L. Bybee, John Haiman and Sandra Thompson (eds.), Essays on language function and language type, pp. 71-113. Amsterdam: John Benjamins.

Dozon, A. 1879. Manuel de la langue chkipe ou albanaise. Paris: Ernest Leroux.

Dryer, Matthew. 2007. Word order. In Timothy Shopen (ed.), Language typology and syntactic description, Vol. I: Clause structure, pp. 61-131. Cambridge University Press. 
2013. A grammatical description of Kara-Lemakot. Canberra: Asia-Pacific Linguistics.

Duponceau, Peter S. 1819. Report of the Corresponding Secretary to the committee of his progress in the investigation committed to him of the General Character and Forms of the Languages of the American Indians - Read, 12th Jan, 1819. In Transactions of the Historical and Literary Committee of the American Philosophical Society, held at Philadelphia, for promoting useful knowledge, Vol. I, pp. xvii-xlvi. Philadelphia: Abraham Small.

Durie, Mark. 1985. A grammar of Acehnese: On the basis of a dialect of North Aceh. (Verhandelingen van het Koninklijk Instituut voor Taal-, Land- en Volkenkunde). Amsterdam: Foris Publications.

1988. The so-called passive of Acehnese. Language 61: 104-13.

Eades, Diana. 1979. Gumbaynggirr. In R. M. W. Dixon and Barry J. Blake (eds.), Handbook of Australian languages, Vol. I, pp. 245-361. Canberra: Australian National University Press; Amsterdam: John Benjamins.

Evans, Nicholas and Stephen C. Levinson. 2009. The myth of language universals: Language diversity and its importance for cognitive science. Behavioral and Brain Sciences 32: 429-92.

Foley, William A. 1998. Anthropological linguistics: An introduction. London: Blackwell Publishers.

Fortescue, Michael. Forthcoming. Polysynthesis. In Nicholas Evans, Michael Fortescue and Marianne Mithun (eds.), The Oxford handbook of polysynthesis. Oxford University Press.

Friedman, Victor A. 2003. Evidentiality in the Balkans with special attention to Macedonian and Albanian. In Alexandra Y. Aikhenvald and R. M. W. Dixon (eds.), Studies in evidentiality, pp. 189-218. Amsterdam: John Benjamins.

2012. Perhaps mirativity is phlogiston, but admirativity is perfect: On Balkan evidential strategies. Linguistic Typology 16: 505-27.

Greenberg, Joseph H. 1963. Some universals of grammar with particular reference to the order of meaningful elements. In Joseph H. Greenberg (ed.), Universals of language, pp. 58-90. Cambridge, MA: MIT Press.

1966. Language Universals, with special reference to feature hierarchies. (Janua linguarum, Series Minor, 59). The Hague: Mouton.

1972. Numeral classifiers and substantival number: Problems in the genesis type. Working Papers in Language Universals; repr. in Greenberg 1990 (pp. 16-93).

1974. Language typology: A historical and analytic overview. The Hague and Paris: Mouton.

1990. On language: Selected writings of Joseph H. Greenberg, ed. K. Denning and S. Kemmer. Stanford University Press.

Haase, Martin. 2001a. Sprachtypologie bei Edward Sapir. In Martin Haspelmath, Ekkehard König, Wulf Oesterreicher and Wolfgang Raible (eds.), 
Language typology and language universals: An international handbook, Vol. I, pp. 264-6. Berlin: Walter de Gruyter.

2001b. Sprachtypologie und Universalienforschung bei Joseph H. Greenberg. In Martin Haspelmath, Ekkehard König, Wulf Oesterreicher and Wolfgang Raible (eds.), Language typology and language universals: An international handbook, Vol. I, pp. 280-3. Berlin: Walter de Gruyter.

Haider, Hubert. 2001. Parametrisierung in der generativen Grammatik. In Martin Haspelmath, Ekkehard König, Wulf Oesterreicher and Wolfgang Raible (eds.), Language typology and language universals: An international handbook, Vol. I, pp. 283-93. Berlin: Walter de Gruyter.

Hammarström, Harald, Robert Forkel, Martin Haspelmath and Sebastian Bank (eds.). 2015. Glottolog 2.5. Leipzig: Max Planck Institute for Evolutionary Anthropology.

Haspelmath, Martin, Matthew S. Dryer, David Gil and Bernard Comrie (eds.). 2005. The world atlas of language structures. Oxford University Press.

Haude, Katarina. 2010. 'She kisses her late husband' = 'She kissed her husband': nominal tense in Movima. In Jan Wohlgemuth and Michael Cysouw (eds.), Rara and rarissima: Documenting the fringes of linguistic diversity, pp. 95-116. Berlin: De Gruyter Mouton.

Hawkins, John A. 1983. Word order universals. New York: Academic Press.

2001. The role of processing principles in explaining language universals. In Martin Haspelmath, Ekkehard König, Wulf Oesterreicher and Wolfgang Raible (eds.), Language typology and language universals: An international handbook, Vol. I, pp. 360-9. Berlin: Walter de Gruyter.

Heine, Bernd and Tania Kuteva. 2001. World lexicon of grammaticalization. Cambridge University Press.

Hewitt, B. G. 1979. Abkhaz. (Lingua Descriptive Studies 2). Amsterdam: North Holland Publishing Company.

Hock, Hans H. 1991. Principles of historical linguistics, 2nd edn. Berlin: Mouton de Gruyter.

2010. Typology and universals. In Silvia Luraghi and Vit Bubenik (eds.), Bloomsbury companion to historical linguistics, pp. 59-69. London: Bloomsbury.

Hopper, Paul J. 1987. Principles of grammaticization: Towards a diachronic typology. In W. P. Lehmann (ed.), Language typology 1987: Systematic balance in language - Papers from the Linguistic Typology Symposium, Berkeley, 1-3 December 1987, pp. 167-80. Amsterdam: John Benjamins.

Humboldt, Wilhelm von. 1836. Über die Verschiedenheit des menschlichen Sprachbaues und ihren Einfluss auf die geistige Entwickelung des Menschengeschlechts. Berlin: Druckerei der Königlichen Akademie der Wissenschaften. 
Jensen, Cheryl. 1999. Tupí-Guaraní. In R. M. W. Dixon and Alexandra Y. Aikhenvald (eds.), The Amazonian languages, pp. 125-64. Cambridge University Press.

Kay, Paul and Chad K. McDaniel. 1978. The linguistic significance of the meanings of basic color terms. Language 54: 610-46.

Kay, Paul, Brent Berlin and William R. Merrifield. 1991. Biocultural implications of color naming. Journal of Linguistic Anthopology 1: 12-25.

Kay, Paul, Brent Berlin, Luisa Maffi, William R. Merrifield and Richard Cook, 2009. World color survey. Stanford: Center for the Study of Language and Information.

Keenan, Edward L. and Bernard Comrie. 1977. Noun phrase accessibility and universal grammar. Linguistic Inquiry 8: 63-99.

Kemmer, Suzanne. 2003. Typology and universals. In William J. Frawley (ed.), International Encyclopedia of Linguistics, 2nd edn, pp. 310-15. Oxford University Press.

Kibrik, A. E. 1977. Opyt strukturnogo opisanija archinskogo jazuka. Tom II. Taksonomicheskaja grammatika [An essay in structural description of Archi. Volume II. Taksonomic grammar]. Moscow: Izdateljstvo Moskovskogo Universiteta.

1994. Archi. In Rieks Smeets (ed.), The indigenous languages of the Caucasus, Part 2, pp. 297-365. New York: Caravan Books.

König, Christa. 2013. Source of information and unexpected information in !Xun: evidential, mirative and counterexpectation markers. In Alexandra Y. Aikhenvald and Anne Storch (eds.), Perception and cognition in language and culture, pp. 65-84. Leiden: Brill.

Kuteva, Tania. 1998. On identifying an evasive gram: Action narrowly averted. Studies in Language 22: 113-60.

Lawler, John M. 1988. On the questions of Acenhese 'passive'. Language 64: 114-17.

Loughnane, Robyn. 2003. Reported speech in Golin (a Papuan language of New Guinea). BA Honours thesis, University of Melbourne.

2005. Reported speech constructions in Golin. In Nicholas Evans, Jutta Besold, Hywel Stoakes and Alan Lee (eds.), Materials on Golin: Grammar, texts and dictionary, pp. 132-51. Department of Linguistics and Applied Linguistics, University of Melbourne.

Mallinson, Graham and Barry J. Blake. 1981. Language typology: Crosslinguistic studies in syntax. Amsterdam: North Holland Publishing Company.

Matthews, P. H. 2007. Concise dictionary of linguistics. Oxford University Press.

Meillet, Antoine. 1926. Linguistique historique et linguistique génerale. Paris: Champion.

Moravcsik, Edith. 2003. A semantic analysis of associative plurals. Studies in Language 27: 469-503.

2011. Explaining linguistic universals. In Jae Jung Song (ed.), The Oxford handbook of linguistic typology, pp. 69-89. Oxford University Press. 
Morpurgo Davies, A. 1975. Language classification in the nineteenth century. In T. A. Sebeok (ed.), Current trends in linguistics, Vol. 13: Historiography of linguistics, pp. 606-716. The Hague: Mouton.

1997. The history of linguistics, Vol. IV: Nineteenth-century linguistics. London: Longman.

Morse, Nancy L. and Michael B. Maxwell. 1999. Cubeo grammar. Studies in the languages of Colombia 5. Arlington: Summer Institute of Linguistics; University of Texas at Arlington.

Newmeyer, Frederick J. 1998. Language form and language function. Cambridge, MA: MIT Press.

Nichols, Johanna. 1986. Head-marking and dependent-marking grammar. Language 62: 56-119.

Nomoto, Hiroki. 2013. Number in classifier languages. PhD dissertation, University of Minnesota.

Nordlinger, Rachel and Louisa Sadler. 2004. Nominal tense in cross-linguistic perspective. Language 80: 776-806.

Ohala, John J. 1975. Phonetic explanations for nasal sound patterns. In C. A. Ferguson, L. M. Hyman and J. J. Ohala (eds.), Nasalfest: Papers from a symposium on nasals and nasalization, pp. 289-316. Stanford: Language Universals Project.

Plank, Frans. 2009. WALS values evaluated. Linguistic Typology 13: 51-76.

Plank, Frans and Wolfgang Schellinger. 1997. The uneven distribution of genders over numbers: Greenberg Nos. 37 and 45. Linguistic Typology 1: 53-101.

Ramat, Paulo (ed.). 1998. Areal typology. Special issue of Language Sciences 20(3).

2011. The (early) history of linguistic typology. In Jae Jung Song (ed.), The Oxford handbook of linguistic typology, pp. 9-24. Oxford University Press.

Sapir, Edward. 1921. Language. New York: Harcourt, Brace and World.

Schlegel, August Wilhelm. 1818. Observations sur la langue et la litérature provençales. Paris: Librairie grecque-latine-allemande.

Schlegel, Friedrich. 1808. Über die Sprache und Weisheit der Indier. Heidelberg: Mohr und Zimmer.

Schleicher, August. 1859. Zur Morfologie der Sprache. Mémoires de l'Académie Impériale des Sciences de St. Petersbourg, ser 4, 1(7): 1-38.

Schultze, Wolfgang M. 2007. Review of The world atlas of language structures, edited by Martin Haspelmath, Matthew S. Dryer, David Gil and Bernard Comrie. Studies in Language 31: 445-63.

Siewerska, Anna. 1984. The passive: A comparative linguistic analysis. London: Croom Helm.

Silverstein, Michael. 1976. Hierarchy of features and ergativity. In R. M. W. Dixon (ed.), Grammatical Categories in Australian Languages, pp. 112-71. Canberra: Australian Institute of Aboriginal Studies. 
Smith-Stark, T. Cedric. 1974. The plurality split. Papers from the Annual Regional Meeting of the Chicago Linguistic Society 10: 657-71.

Smythe, W. E. 1948/9. Elementary grammar of the Gumbaingar language (north coast, N. S. W.). (Oceania Monograph 8). Sydney: Australian National Research Council.

Storch, Anne. 2013. Knowing, smelling and telling tales in Luwo. In Alexandra Y. Aikenvald and Anne Storch (eds.), Perception and cognition in language and culture, pp. 47-68. Leiden: Brill.

Tida, Syuntarô. 2006. A grammar of the Dom language, a Papuan language of Papua New Guinea. PhD thesis, University of Kyoto.

Tonhauser, Judith. 2007. Nominal tense? The meaning of Guaraní nominal temporal markers. Language 83: 831-69.

2008. Defining cross-linguistic categories: The case of nominal tense. Reply to Nordlinger and Sadler (2008). Language 84: 332-42.

Uusküla, Mari and Urmas Sutrop. 2010. The puzzle of two terms for red in Hungarian. In Jan Wohlgemuth and Michael Cysouw (eds.), Rara and rarissima: Documenting the fringes of linguistic diversity, pp. 359-76. Berlin: De Gruyter Mouton.

Vennemann, Theo. 1974. Theoretical word order studies: Results and problems. Papiere zur Linguistik 7: 5-25.

Zeshan, Ulrike. 2004. Interrogative constructions in signed languages: Cross-linguistic perspectives. Language 80: 7-39. 